\title{
Early Modernism
}

The New Woman

Towards the end of Honeycomb (1917), the third volume of Dorothy Richardson's Pilgrimage (1915-1938), her protagonist Miriam Henderson identifies herself through a plume of cigarette smoke as 'a new woman' (PI 436). This new subject position is troubling, however, leading her to ponder how she is to 'reconcile the role with her work as a children's governess' (PI 436). The much vaunted independence of the New Woman sits uneasily with the traditional female job of governess, not least because the latter typically functioned as the guardian of the gendered social norms that the former was ostensibly challenging. In fact, the New Woman was a complex and contradictory figure, as the numerous novels written by and about her amply attest. Her critics saw her as an iconoclastic, unnatural, and anarchic figure bent on inverting time-honoured sexual roles and destroying the patriarchal family in the process, but New Woman writing was often conservative, seeking to educate women, rehabilitate men, and reform the institution of marriage rather than overthrow it. But it was easy to overlook this aspect of New Woman writing and to focus on its more sensational elements, especially its interest in female sexuality. Various forms of behaviour (smoking, dressing 'mannishly', wearing make-up, living in rented flats, attending free-thinking artistic salons, riding bicycles) were seen by outraged commentators as the manifestations of a disturbing intellectual independence and also of dubious sexual morals. Thomas Hardy in Jude the Obscure (1895) described his

A History of Modernist Literature, First Edition. Andrzej Gąsiorek.

(C) 2015 Andrzej Gąsiorek. Published 2015 by John Wiley \& Sons, Ltd. 
character Sue Bridehead as a "woman of the feminist movement - the slight, pale "bachelor" girl - the intellectualized, emancipated bundle of nerves that modern conditions were producing', thereby making the link between the New Woman and the politics of gender. ${ }^{1}$ Other writers, most notably George Egerton (Mary Chavelita Dunne), stressed the New Woman's active sexuality, an emphasis that drew insults and opprobrium.

The origins of cultural phenomena are hard to identify with precision. Olive Schreiner's The Story of an African Farm (1883) is often taken to be the first novel in a genre that includes (among many others) such key texts as Grant Allen's The Woman Who Did (1895), Mona Caird's The Daughters of Danaus (1894), Mary Cholmondeley's Red Pottage (1899), Gertrude Dix's The Image Breakers (1900), Menie Muriel Dowie's Gallia (1895), Isabella Ford's On the Threshold (1895), George Gissing's The Odd Women (1893), Thomas Hardy's Jude the Obscure (1895), Ella Hepworth Dixon's The Story of a Modern Woman (1894), and Netta Syrett's Nobody's Fault (1896). In the wake of the Wilde trial in 1895 and the scandal it generated, New Woman fiction went into decline, but it would be a mistake to think it died out entirely, for not only did novels in the genre continue to be written but also its influence is discernible on a number of early twentiethcentury works, among them Bryher's Development (1920) and Two Selves (1922), E. M. Forster's Howards End (1910), D. H. Lawrence's Sons and Lovers (1912), The Rainbow (1915), and Women in Love (1920), Dorothy Richardson's Pilgrimage (1915-1967), May Sinclair's The Creators (1910) and The Three Sisters (1914), H. G. Wells's Ann Veronica (1909), Virginia Woolf's The Voyage Out (1915), and Ford Madox Ford's Parade's End tetralogy (1924-1928). New Woman fiction was a genre in its own right and also a source for twentieth-century modernism, which both reacted against this powerful precursor and transformed it. ${ }^{2}$ Bonnie Kime Scott argues that we need to recognise the ways in which 'modernism was inflected $[\ldots]$ by gender', and this recognition leads us to see how a modernism 'caught in the mesh of gender is polyphonic, mobile, interactive, sexually charged'. ${ }^{3}$

Although New Woman fiction took a variety of forms and comprised a range of political positions, it was associated with a wider drive for social change. New Women were linked with a desire for independence and education, equality between men and women, reform (rather than abolition) of marriage, criticism of sexual hypocrisy, the right to be 
able to work on equal terms with men, the struggle for the franchise, class politics, a rethinking of women's 'nature' and their social roles, and, somewhat contradictorily, at times a call for full sexual freedom and at others an emphasis on purity for both genders. The novelist Sarah Grand, author of The Heavenly Twins (1893) and The Beth Book (1897), maintained in 'The New Aspect of the Woman Question' (1894) that the New Woman wanted to challenge long-established gender assumptions, argue in favour of sexual purity for both genders, and suggest that a reciprocal model of male-female relations was required, since 'there are in ourselves, in both sexes, possibilities hitherto suppressed or abused, which, when properly developed, will supply to either what is lacking in the other'. ${ }^{4}$ This is a rather safesounding reformist account. Ella Hepworth Dixon, in contrast, argued that by gaining independence the New Woman had freed herself from the need to marry at all. This suggested that a more far-reaching challenge to sexual hierarchies was being mounted: 'If young and pleasing women are permitted by public opinion to go to college, to live alone, to travel, to have a profession, to belong to a club, to give parties, to read and discuss whatsoever seems good to them, and to go to theatres without masculine escort, they have most of the privileges $[\ldots]$ for which the girl of twenty or thirty years ago was ready to barter herself to the first suitor who offered himself and the shelter of his name'. ${ }^{5}$ According to this view, marriage was little more than a form of legalised prostitution; if women were now free to do the things many had longed to do for years, then what need was there for the institution of marriage? In short, Grand's stress on 'purity' for both sexes and on the reform of marriage was not shared by all who engaged with the New Woman question, just as the Pankhursts' puritan view of sexual morality was criticised by feminists in the 1910s. It is clear that, as Jane Eldridge Miller puts it, 'there is no single type who is the rebellious woman' in this period; there were, rather, various rebels and reformers who frequently disagreed with one another about the nature of the dilemmas confronting them. ${ }^{6}$

The more radical figure described by Hepworth Dixon was widely perceived as a social threat. This kind of New Woman - outspoken, hard-headed, and open-minded - was associated with decadence, degeneration, and anarchy. Her feminism was interpreted by defensive commentators as 'a sign of decay and corruption' that would doom civilisation to decline, and it was feared that her egotistical desire for 
autonomy would cause 'incalculable upheaval and destruction'. ' The New Woman was also sexually ambiguous. She could be portrayed either as a sexually forward minx or as a bloodless brainbox with an aversion to sex. Jude's Sue Bridehead would be an example of the latter type, as would Ann Veronica's Miss Miniver, who, in contrast to the heroine's ardour - 'Hot-blooded marriage or none!' - longs for a purely spiritual relationship: 'Bodies! Bodies! Horrible things! We are souls. Love lives on a higher plane. We are not animals'. ${ }^{8}$

To her critics, the New Woman was a perverse and decadent being who betrayed her innate nature and her purpose in life: to be a dutiful daughter and wife, bear children, act as a help-meet to her husband, and sanctify the home with her dewy-eyed idealism. The New Woman's independence threatened a society that relied on distinct gender roles and the cultural assumptions that underpinned them. Numerous commentators deplored her demand for independence, and her candid interest in politics, social questions, and sexuality led her to be denounced in some quarters as a licentious degenerate. The New Woman, moreover, was also frequently seen as but one instance of a wider process of cultural (perhaps even biological) decline. Following B. A. Morel, who saw degeneration as 'a morbid deviation from an original type', Max Nordau, for example, argued in his widely read Degeneration (1895) that 'all the fin-de-siècle movements in art and literature' revealed their proponents' fundamental decadence. ${ }^{9}$

Opponents of the New Woman and her supposedly destructive ideas were hostile not only to her independent life in the modern city but also to her pernicious reading habits. Radical books were the enemy. It is no surprise, then, that fierce battles were fought in the $1880 \mathrm{~s}$ and 1890s over censorship. Hardy's problems with Jude the Obscure were part of a wider struggle with circulating libraries and booksellers like W. H. Smith, both of which exercised a good deal of control over people's access to books. However, worries about the consequences of indiscriminate reading and disputes over candour in fiction were prevalent throughout the fin-de-siècle period. ${ }^{10}$ Wells registered these concerns in Ann Veronica when his heroine's father - a reader of 'healthy light fiction' - inveighs against 'damned novels': 'All this torrent of misleading, spurious stuff that pours from the press. These sham ideals and advanced notions, Woman who Dids, and all that kind of thing'. ${ }^{11}$ It's no surprise, then, that in Pilgrimage Miriam Henderson reads various New Woman authors - Mary Cholmondeley (P2 268) and Olive 
Schreiner (P2 241) among them - nor that her imaginative life is stimulated by the sensational works of 'Ouida', the risqué novelist who, in Sally Ledger's words, 'extrapolated the now famous - and then infamous - phrase "the New Woman" from Sarah Grand's essay, "The New Aspect of the Woman Question"" and gave it popular currency. ${ }^{12}$

Conservative critics of the New Woman and what she heralded typically appealed to essentialist arguments about women's supposedly immutable character. Feminists tended to dismiss such crude claims on theoretical grounds. Harriet Taylor and John Stuart Mill had argued in the 1850s that assumptions about innate differences between the genders were intellectually spurious. Fin-de-siècle feminists shared their views. Mona Caird, noting that 'innumerable contradictory dogmas' were held about 'woman's nature', maintained that in fact 'there is so little really known about it, and its power of development, that all social philosophies are more or less falsified by this universal though sublimely unconscious ignorance'. ${ }^{13}$ The most challenging New Woman novels sought to open up the issue of gender identity, suggesting that what men and women might be or might yet become was not a resolved question but an unknown prospect. The New Woman fiction that has the closest affinities with twentieth-century modernism - Schreiner's The Story of an African Farm, for example, or Egerton's Keynotes and Discords - explores this indeterminacy not just thematically but also through new approaches to style, form, and characterisation.

The Story of an African Farm explores the difficulties faced by a potent woman determined to break free from an oppressive existence. In keeping with its protagonist's refusal to conform to expected behavioural codes, the novel challenged the realist canons of what Schreiner called the 'stage method' (in which textual conflicts are resolved in a satisfying closure). There was, she wrote, 'another method' - a method that did justice to 'the life we all lead'. This life, she argued, is unpredictable ('nothing can be prophesied') and formless (people 'appear, act and re-act upon each other, and pass away'). In life, Schreiner went on, when 'the curtain falls no one is ready', and this claim implies that clear-cut conclusions about human existence falsify its contingent nature. ${ }^{14}$ Schreiner was making a case for literary recognition of the discontinuities and indeterminacies that would become a marked feature of modernist writing in the decades to come. By doing so, she was undermining the conventions of nineteenth-century realism, her implicit claim being that only by 
means of innovative techniques could the complexity of modern existence be rendered properly. Ruth Robbins suggests that The Story of an African Farm prefigures modernist experimentation in its blending of different genres and its 'aesthetics of displacement and fragmentation'. ${ }^{15}$

George Egerton - the pen name of Mary Chavelita Dunne - is another writer whose work challenged the conservative belief in female decorum. Born in Australia, Egerton lived an itinerant existence in various countries and had several relationships (including with the Norwegian writer Knut Hamsun, to whom Keynotes was dedicated), before she moved to London in 1894 and immersed herself in its advanced literary circles. Influenced by Ibsen and Strindberg, Egerton evolved an introspective and reflective style through which she explored the workings of the psyche, male-female relationships, and women's sexuality. Her Keynotes (1893) and Discords (1894) are among the few fin-de-siècle works that were bold in the subjects they tackled and also formally experimental, eschewing plot and relying on inconclusive dialogues and internal fantasies. In Egerton's stories, all is atmosphere, discussion, musing, suggestiveness. Keynotes was received by some as a quintessentially woman's book, one reviewer suggesting that it was written 'against' men and 'for our own private use'. ${ }^{16} \mathrm{~A}$ favourite technique was the use of the present tense, which places events in an ongoing present rather than consigning it to a completed past. Egerton's impressionistic and oblique style suggests that she should be seen as a key modernist progenitor.

Egerton was interested not in some spurious defence of sexual purity but in describing female desire. In 'A Cross Line', her protagonist longs to escape the oppressive constraints imposed on her by her gender: 'I wish I were a man! I believe if I were a man, I'd be a disgrace to my family' (KD 7). This adoption of the male subject position is linked to the idea of a transgressive (shaming) behaviour that is sexual in nature, since the protagonist is soon involved in an erotically charged scene in which her husband 'snatches her up' while his 'eyes dilate and his colour deepens as he crushes her soft little body to him and carries her off to her room' (KD 8). The woman might seem to be passive in this scene, but in fact she has been the more active figure prior to this moment. Interestingly, however, her vitality is associated with masculinity. 'Perhaps I was a man last time', she speculates, and then, 'kneeling up, [she] shuts his eyes with kisses, and bites his chin and shakes it like a terrier in her strong little teeth' (KD 8). 
Like many New Woman characters, this protagonist longs to escape from entrapping domesticity. This desire is articulated through an exoticising primitivist language. Imagining herself 'in Arabia on the back of a swift steed', the woman shapes her thoughts into an atavistic song, 'an uncouth rhythmical jingle with a feverish beat; a song to the untamed spirit that dwells in her' (KD 8). This primitivism both sexualises the character and lies at the heart of her views about women's nature, which in this text is portrayed as an 'eternal wildness, the untamed primitive savage temperament that lurks in the mildest, best woman' (KD 9). This temperament, we are told, is an unalterable quality that no amount of socialisation will ever destroy: 'Deep in through ages of convention this primeval trait burns, an untameable quantity that may be concealed but is never eradicated by culture - the keynote of woman's witchcraft and woman's strength' (KD9).

Such sentiments frequently crop up in the literature of the period, perhaps most notably in Conrad's depiction of the African queen in Heart of Darkness (1899), but also in such works as D. H. Lawrence's Women in Love (1920) and The Plumed Serpent (1926), Rebecca West's 'Indissoluble Matrimony' (1914), and Katherine Mansfield's 'Je Ne Parle Pas Français' (1920). These texts speak to anxieties about atavism and the danger of reversion to more 'primitive' states (as in Stevenson's doubled Jekyll and Hyde character), but they also tap into seductive theories about the revitalising power of 'primitivism', which feature in such modernist movements as Cubism, Expressionism, Italian Futurism, and Vorticism. In 'A Cross Line', primitivist discourse is aligned with animalistic vitality and a gendered will to power. In an interesting inversion of the expected association of masculinity with virility, Egerton suggests that male effeteness is responsible for the subjection of women: 'if it were not for that, we women would master the world. I tell you men would be no match for us. At heart we care nothing for laws, nothing for systems. All your elaborately reasoned codes for controlling morals or man do not weigh a jot with us against an impulse, an instinct. We learn those things from you, you tamed, amenable animals; they are not natural to us' (KD 11).

This is a long way away from Grand's faith in equality and education. Egerton's stress on elemental energy has affinities with the egoist philosophies expounded by such figures as Nietzsche and the less wellknown Max Stirner - which, as we will see, play a significant role in the work of later modernists - drawing on a primitivism that aims to regenerate society. Havelock Ellis, for one, hoped that the New Woman 
would accomplish 'a reinvigoration as complete as any brought by barbarians to an effete and degenerating civilization'. ${ }^{17}$ Schreiner, who was close to Ellis, echoed Egerton's sentiments throughout her sociological work Woman and Labour (1911), which operates with an unusual praise/blame model. For Schreiner, women are on the one hand the custodians of a life-enhancing power that makes them superior to men, but on the other hand, both male weakness and social decline are somehow women's fault, caused by their degeneration. Schreiner seeks to recall the women of antiquity and to align them with the feminists of the turbulent present. The New Woman 'is essentially but the old non-parasitic woman of the remote past, preparing to draw on her twentieth-century garb', and her future depends on her capacity to get back in touch with her lost history. ${ }^{18}$

These kinds of arguments were interpreted by opponents of New Women as indications of their anarchic and decadent tendencies. The point is an important one, since anarchism and decadence were much debated at the fin de siècle and were associated in many people's minds with threats to the social order. Numerous commentators saw a link between the New Woman's disturbing interest in sex and its questionable social consequences. Hugh Stutfield wrote in 'Tommyrotics' (1895) that Egerton's Discords was 'a fair type of English neurotic fiction' and asserted that 'the woman of the new Ibsenite neuropathic school is not only mad herself, but she does her best to drive those around her crazed also'. For Stutfield, such writing demonstrated that New Women were unbalanced and damaged the wider body politic: 'Along with its diseased imaginings - its passion for the abnormal, the morbid, and the unnatural - the anarchical spirit broods over all literature of the decadent and "revolting" type. It is rebellion all along the line. Everybody is to be a law unto himself'. ${ }^{19}$ The same point was made by Elizabeth Chapman in her account of Mona Caird's The Daughters of Danaus (1894). Its protagonist was said to be 'in full rebellion not merely against institutions' but 'against law qua law, against authority qua authority'. ${ }^{20}$

New Woman fiction was attacked not just for its dangerous subject matter but also for its formlessness. W. L. Courtney associated it with a perverse interest in unnecessary detail, which, he argued, was the corollary of an excessive subjectivism that turned women's fiction into a diary-like (and thus artless) expression of self. Virginia Woolf responded to this charge in an early review. She argued that while the value of new women's writing was as yet impossible to determine, the 
claim that it was destroying 'the novel as a work of art' was a questionable assertion. For Woolf, any lack of structure that women's fiction displayed could be attributed to a lack of instruction; once gained, education might give the woman writer 'that sterner view of literature which will make an artist of her, so that, having blurted out her message somewhat formlessly, she will in due time fashion it into permanent artistic shape' (VWI 16). Woolf would still be grappling with the problem of the relationship between form and content in A Room of One's Own (1928), in which the question of how the blank sheet of paper was to be filled in by the newly enfranchised woman writer continues to loom large. ${ }^{21}$

But in the late nineteenth-century context, accusations about trivial detail and consequent formlessness implied that New Woman fiction was decadent, since decadent style was seen to represent a morbid interest in the trivial 'part' at the expense of the significant 'whole'. In Arthur Symons's influential account, classicism exemplified 'perfect simplicity, perfect sanity, perfect proportion, the supreme qualities', whereas decadence disclosed 'an intense self-consciousness, a restless curiosity in research, an over-subtilizing refinement upon refinement, a spiritual and moral perversity'. ${ }^{22}$ Interest in minutiae was seen as a sign of excess in such accounts because it was thought to disclose an unhealthy obsession with obscurity at the expense of clarity, a kind of weird fascination with the irrelevant detail instead of the significant whole. But another way of thinking about this problem is to see it as a strategy of teasing out particular issues, of focusing on the isolated strand in order to see where it leads and to grasp what role it plays in a wider system or structure. To unravel cultural threads and to suggest that they are woven together in one way but could be plaited differently is to challenge the social status quo and to disturb the norms upon which it depends. When writers at the fin de siècle exposed the linked assumptions that underpinned normative constructions of gender identity, they questioned the whole framework of patriarchal society. Capes in Ann Veronica puts it as follows: 'Men and women are not established things; they're experiments, all of them'. ${ }^{23}$ Lyndall in The Story of an African Farm states: 'When I am with you, I never know that I am a woman and you are a man; I only know that we are both things that think'. ${ }^{24}$

But the critics who discerned in New Woman fiction an interest in revolt (as opposed to reform) and an exaltation of ego-driven individualism were not entirely wide of the mark. There is a vitalist strain in a 
good deal of New Woman writing, perhaps most obviously in work by Egerton, Schreiner, and Wells, and this strain is also visible in different ways in the later modernism of Henri Gaudier-Brzeska, T. E. Hulme, D. H. Lawrence, Dora Marsden, Wyndham Lewis, Ezra Pound, and Rebecca West. Joseph Conrad ridiculed it in The Secret Agent (1907), where (with a nod to Max Nordau and his mentor Cesare Lombroso) it is ironised as the deluded raving of society's most decrepit elements. But the intense focus on the self in a good deal of New Woman writing should not be seen as solely, or even primarily, about the assertion of ego power. It discloses a desire to explore, as though for the first time, the inner reality of gendered experience.

Egerton was explicit about this dimension of her work: 'I realised that in literature, everything had been done better by man than woman could hope to emulate. There was only one small plot left for her to tell: the terra incognita of herself, as she knew herself to be, not as a man liked to imagine her - in a word, to give herself away'. ${ }^{25}$ Egerton emphasises the writer's agency and foregrounds her project of reclamation. Women's experiences are no longer to be narrated by those who cannot fathom them but are to be articulated on their own terms and in their own language. The study of the self in another story from Keynotes ('Now Spring Has Come') teaches the protagonist that 'the untrue feminine is of man's making, whilst the strong, the natural, the true womanly is of God's making' (KD 16). This statement has an essentialist ring to it, and Egerton's desire to explore womanliness in a new language and style bears comparison with Dora Marsden's writings for The Freewoman and The New Freewoman in the years leading up to the First World War, Dorothy Richardson's treatment of gender in Pilgrimage, and Bryher's concerns in Development. We should note as well that several 'modern' novels - for example Elizabeth Robins's The Convert (1907), Charlotte Despard's and Mabel Collins's Outlawed: A Novel on the Woman Suffrage Question (1908), Constance Maud's No Surrender (1911), Cicely Hamilton's William - An Englishman (1919), Virginia Woolf's Night and Day (1919), and John Cournos's Babel (1922) - addressed the question of the suffrage and explored the dilemmas faced by the suffragettes, even though they were not technically and formally as inventive as the texts produced by Bryher, Loy, Richardson, and the later Woolf.

Richardson observed that as she reflected on her creative process during the writing of Pilgrimage, her initial preoccupations fell away, 'a stranger in the form of contemplated reality having for the first time in 
her experience its own say, and apparently justifying those who acclaim writing as the surest means of discovering the truth about one's own thoughts and beliefs' (PI 10). In Bryher's Development (1920), her protagonist is 'filled with her own manuscript, wrought neither of imagination nor remembered stories but of the one experience she knew from end to end - herself' (DTS 169). All three novelists developed innovative literary forms to explore this terra incognita, as did others in the years to come, Djuna Barnes, H.D., Mina Loy, Jean Rhys, Una Marson, May Sinclair, and Virginia Woolf among them. Sinclair captured their shared sense that questions of form, language, style, and convention were at stake here in her early review, 'The Novels of Dorothy Richardson' (1918): 'Reality is thick and deep, too thick and too deep, and at the same time too fluid to be cut with any convenient carving knife' ${ }^{26}$

\section{Literary Impressionism}

Sinclair's sense that reality was too complex to be understood easily lies at the heart of literary impressionism, an approach to writing that is closely associated with such figures as Conrad, Stephen Crane, Ford, and Henry James in the late 1890s and early 1900s and that was then taken up and adapted by Richardson and Woolf between the 1910s and the 1930s. This group of writers can be seen as a community of writers (for a period of time in the late 1890 s, they lived in close proximity to each other around Romney) who were all, to some degree, outsiders, in terms both of their nationalities (they included one Pole and two Americans) and of the challenge they were mounting to late Victorian and Edwardian literary conventions. Conrad was acutely conscious of his 'foreignness' and was touchy about readings of his books that emphasised it, while James's extended preoccupation with the clash of American and European cultures registered a changed transnational orientation in the fiction of the period..$^{27}$ More than most contemporaneous commentators, it was Ford who insisted that the conscious artistry these writers practiced had to be seen as a rejection of haphazard 'English' literary methods and as a sign of their commitment to a properly international conception of the arts. ${ }^{28}$ Claiming that at a time when attention to questions of literary technique was regarded as a kind of 'vice', Ford remarked of James and Conrad that 'no two other writers, functioning together, were consciously and so exclusively preoccupied with those dangerous topics' ${ }^{29}$ 
Sinclair's reference to a 'convenient carving knife' indicates that she was thinking about the failure of all literary methods and conceptual schema to get to grips with reality. By doing so, she was drawing attention not just to the act of perception (difficult enough) but to the problem of form, since she was acknowledging that all fictional accounts of reality were rendered through particular styles and techniques. Literary impressionism was centrally concerned with this problematic relationship between cognition and language or form (it was a key feature of Conrad's and Ford's writing especially), but it was also preoccupied with the implications of this vexed relationship for the morality of the novel, which they saw as a questing and radically openended genre.

In The Importance of Being Earnest, Oscar Wilde mocked the Victorian assumption that novels should point a clear moral when one of his characters observes of a novel she has been reading: 'The good ended happily, and the bad unhappily. That is what Fiction means'. ${ }^{30}$ For impressionist novelists, it meant nothing of the sort. Impressionist fiction is associated not only with various formal innovations but also with scepticism about numerous nineteenth-century moral assumptions. Ford Madox Ford wrote that the modern novel registered 'the definite facts of a story, leaving to the reader the task of adopting what moral attitude he will towards a given set of circumstances', and he defined this approach as representative of 'the modern canon' (CA 97). For Ford, this agnostic approach improved on morally earnest Victorian fiction in two ways: it was artistically superior because it subordinated ethical issues to aesthetic considerations, and it was intellectually more serious because it did not generalise about the social and moral problems it explored. This was a defence of a relativistic modernism that for Ford was indelibly associated with the literary impressionism that he himself favoured.

Like the wider modernism of which it is a significant part, literary impressionism has proved hard to define, not least because it was deployed by a number of writers, some of whom expressed reservations about being grouped together under its banner. It is best thought of as a heuristically useful concept that is somewhat fuzzy around the edges. But literary impressionism is important to modernism and plays a significant role in the work of such writers as Conrad, Ford, Richardson, and Woolf. In its first phase (Conrad and Ford), it is associated with temporal dislocation, tightly controlled and usually restricted narrative points of view, fleeting and unreliable perceptions, 
suppression of authorial commentary, the search for the mot juste, the carefully prepared progression d'effet, and aesthetic autonomy.

Ford was impressionism's most vocal champion, and he was keen to annexe both Conrad and James to his cause, though both these writers distanced themselves from impressionism in subtle ways. Above all, impressionism was concerned with the act of perception; it drew attention to the mental processes by which the world was apprehended. By doing so, it stressed the subjective nature of cognition, thereby moving away from the relatively stable perspectives of realist fiction, and also focused on the role of language and form in all narrative acts. The inward turn, in other words, was connected to a linguistic turn; the question of how a specifically placed individual made sense of the world was inseparable from the issue of discovering the discourses and narrative modes through which human perception might best be articulated and communicated. The Good Soldier's firstperson narrator remarks that he does not 'know how it is best to put this thing down' (GS 15) and asks '[w]ho in this world knows anything of any other heart - or of his own?' (GS 104), Marlow in Heart of Darkness feels that 'it is impossible to convey the life-sensation of any given epoch of one's existence, - that which makes its truth, its meaning - its subtle and penetrating essence' (HD 130), and Wells's protagonist in Tono-Bungay announces: 'It isn't a constructed tale I have to tell but unmanageable realities'. ${ }^{31}$

Impressionism invokes realism, offering itself as 'a more subtle, more effective form of it', but also is aligned with Futurism and thus 'points forwards, towards Modernism'. ${ }^{32}$ Ford's impressionism troubles periodising accounts that posit a break between modernism and the Victorian period 'by telling a story of continuities from the 1850s to the 1930s', with a focus on Flaubert, Maupassant, Stendhal, and Turgenev, rather than one of 'paradigm shifts and epistemological fractures. ${ }^{33}$ Ford traces impressionism back to a tradition of conscious artistry that he locates in Europe and that then, via such writers as Joseph Conrad, Stephen Crane, and Henry James, migrates to England. This tradition, in turn, with its emphasis on subjective perception and multiple viewpoints, looks forward to the inward turn we associate with Joyce, Richardson, and Woolf, the latter arguing in the 1920s that the novelist should strive to render justice to the 'myriad impressions' that shower down on the perceiving mind. ${ }^{34}$

A further point to note here is that Ford's obsession with literary technique and conscious artistry has affinities with a nineteenth-century 
'purism' that extends as far back as Théophile Gautier's Mademoiselle de Maupin (1835). Arguments in favour of the autonomy of art were made by Yeats and the Rhymers, by assorted impressionists associated with the circle around W. E. Henley, by Wilde and the Aesthetes, by Thomas Hardy, and by George Moore. Several nineteenth-century 'purists' argued from the 1880s onwards that the novel was not primarily a mode of moral inquiry and therefore should be free from censorship and frank about the changing nature of sexual relationships, while remaining a sedulously planned artistic form. ${ }^{35}$ In keeping with this tradition's belief that beauty trumped utility every time, Ford on occasion suggested that he was 'interested only in how to write' and that he cared 'nothing - but nothing in the world! - what a man writes about' (FCW xi-xii). This polemical overstatement chimes with Flaubert's conviction that 'from the standpoint of pure Art one might almost establish the axiom that there is no such thing as subject - style in itself being an absolute manner of seeing things' (GFL 154). ${ }^{36}$ The 'things' to be observed in this conception of art are less important than the 'manner' in which they are seen and evoked.

A key tenet of Ford's theory of impressionism was that the author's presence must be suppressed. This stricture wasn't intended to promote the kind of omniscient objectivity associated with realist styles but rather to ensure that the fictional illusion would remain unbroken. Impressionism was to brook no interference from an intrusive author but was to create a seamless fictional world out of subjective and partial perceptions. Ford saw impressionism as a narrative mode that had the capacity to render human perplexity, especially about the motives and behaviour of other people, a key modernist concern. Impressionism responded to what Ford saw as the inescapably subjective nature of human perception; it also provided a technique for exploring the changes being brought about by a rapidly modernising society. These two aspects of impressionism ratified a questioning, open-ended, modernist fictional mode. Impressionism's impatience with didacticism and moralism manifested itself in the techniques it deployed to enter imaginatively into human dilemmas, leaving readers to make their own interpretations and judgements. This was a dialogic conception of fiction that was orientated to the confusion of everyday life and that explored psychological bafflement, social fragmentation, and cultural change.

Ford's claim that the modern novel broke with the dominant Victorian view of it was a self-serving one. He wanted to drive a wedge between a rigorous Flaubertian approach to the art of fiction 
and a looser, more informal practice that in his view lacked seriousness. But several of Ford's arguments had been made in the Victorian period, for example, by Hardy, Moore, and Wilde. Ford's belief in the autonomy of art was shared by Conrad and James, who both insisted that their work should not be judged according to ethical criteria, though their novels were preoccupied with moral questions. James mocked Walter Besant's simplistic assumptions about the morality of the novel in 'The Art of Fiction' (1884). He argued that novels failed to do justice to the enigmatic nature of reality when they were too tidily ordered, and he insisted that critics who tried to fit fiction to some kind of moral schema misunderstood how it worked: 'Will you not define your terms and explain how (a novel being a picture) a picture can be either moral or immoral? You wish to paint a moral picture or carve a moral statue: will you not tell us how you would set about it? We are discussing the Art of Fiction; questions of art are questions $[\ldots]$ of execution; questions of morality are quite another affair, and will you not let us see how it is that you find it so easy to mix them up?'37

For James, these were such difficult issues that Besant's claim to have solved them merited only scorn. Far from showing an ethical sensibility at work, James drily observed, English fiction - beset as it was by the censorship against which Hardy and Moore railed was characterised not by ethically challenging work but by 'moral timidity', 'diffidence', and an 'aversion to face the difficulties with which on every side the treatment of reality bristles'. ${ }^{38}$ Conrad, in turn, wrote in A Personal Record (1912) that he had never sought 'to reprove mankind for what it is, or praise it for what it is not, or generally - to teach it how to behave', while in a letter to Edward Noble he rejected 'all formulas dogmas and principles of other people's making', arguing that human variety turned such general principles into 'a web of illusions'. ${ }^{39}$ Like Ford and James, he believed that art was valuable because it engaged with reality in all its baffling complexity.

Ford recognised that the modernity of early twentieth-century fiction needed to be traced back to the nineteenth century. His main touchstones were Flaubert, James, Maupassant, Stendhal, and Turgenev. Missing from this list is Hardy, the writer on whose behalf Ford allegedly started The English Review because no other magazine would publish his poem 'A Sunday Morning Tragedy', though Ford claimed he did this not to 'sav[e] the Nation' but to promote 'what 
was then Literary Modernism' ${ }^{40}$ Hardy is important to modernism because his thinking about the novel has affinities with Ford's impressionism and because he influenced D. H. Lawrence, whose Study of Thomas Hardy (1914) represents an interesting working through of the influence on one writer of a strong precursor. But if Hardy does not figure prominently in Ford's pantheon, then others were quick to identify him as a new type of writer. ${ }^{41}$ Lionel Johnson argued in The Art of Thomas Hardy (1894) that the modern novel was 'concerned, not with the storm and stress of great, clear, passions and emotions, but with the complication of them'; the new fiction was characterised by 'confused conflict', he wrote, and Hardy was a writer who stressed 'the complexity of things, the clash of principles and of motives, the encounter of subtile [sic] emotions'. ${ }^{42}$

James, by contrast, was in the main frustrated by Hardy's fiction. He discerned George Eliot's influence on Far From the Madding Crowd (1874), but overall he thought the novel was a formless and inartistic hotch-potch. ${ }^{43}$ Hardy, moreover, was symptomatic of a wider problem. His over-stuffed work exposed the limitations of the three-decker format, leading James to propose the temporary introduction of 'a few arbitrary rules - a kind of depleting process' by means of which the Victorian novel could be purged of its garrulousness so that attention could be shifted 'rather more severely from quantity to quality'. He remarked caustically: 'Almost all novels are greatly too long, and the being too long becomes with each elapsing year a more serious offence'. ${ }^{44}$ James was appealing for linguistic economy and artistic precision. In his view, the exhaustive details that were supposed to give social depth to Victorian fiction distracted readers from novels' narrative purposes and vitiated their form. His criticism of the piling up of unnecessary contextual information (a charge he repeated when he discussed the work of a new generation of writers in his 1914 essay 'The Younger Generation') is an early instance of a strand in modernism that is sceptical about the aesthetic value of social details that are not incorporated into an artistic design. Virginia Woolf made the same point in her later polemics against 'materialist' authors, as did Wyndham Lewis in his critique of James Joyce's reliance on naturalism in Ulysses (1922).

Yet Hardy was sceptical about realism as well. It is ironic that James's criticisms of Hardy's writing echo the latter's reservations about nineteenth-century fiction. Art, Hardy insisted, 'is a disproportioning - (i.e., distorting, throwing out of proportion) - of realities, to 
show more clearly the features that matter in those realities, which, if merely copied or reported inventorily $[\ldots]$ would $[\ldots]$ probably be overlooked. Hence "realism" is not art' ${ }^{45}$ Hardy did not see himself as a realist. He sought to portray the far-reaching changes taking place in a particular region of England, but his primary objective was to be faithful to his personal impressions. He understood the transformation of life in the countryside better than any other late nineteenth-century writer, explored its shifting patterns of labour, and focused on the erosion of local traditions, customs, and dialects, all of which disclosed what he saw as 'a break of continuity in local history' (HPW 10). But his fictional oeuvre offered a subjective response to the changing landscape of late Victorian society. In the 1895 preface to Jude the Obscure, Hardy described his work as 'an endeavour to give shape and coherence to a series of seemings, or personal impressions' (HPW 32-33), and this account of impressionism was his defence against those who convicted him of expounding a consistent worldview through his novels. 'I have no philosophy', he wrote, 'merely what I have often explained to be only a confused heap of impressions, like those of a bewildered child at a conjuring show'. ${ }^{46}$

Like Ford, whose theory of impressionism depended on the initial 'uncorrected' perception, Hardy was interested in communicating the haphazard nature of perceptual experience. 'Unadjusted impressions have their value', he wrote, 'and the road to a true philosophy of life seems to lie in humbly recording diverse readings of its phenomena as they are forced upon us by chance and change' (HPW 39). Despite 'the claims of realism', Hardy wrote, 'the best fiction, like the highest artistic expression in other modes, is more true, so to put it, than history or nature can be' (HPW 117). This was a defence of mimesis. Hence Hardy's frequent insistence that the novel should not be compared with photography, which, he argued, rendered the surface of social life but could not evoke its hidden mysteries. Hardy's criticisms of social realism are almost identical to those later made by Woolf in 'Modern Fiction':

There are certain novels $[\ldots]$ which give convincing proof of much exceptional fidelity, and yet they do not rank as the greatest productions; for what they are faithful in is life garniture and not life. You are fully persuaded that the personages are clothed precisely as you see them clothed in the street, in the drawing-room, at the assembly. Even the trifling accidents of their costume are rendered by the honest narrator. 
They use the phrases of the season, present or past, with absolute accuracy as to idiom, expletive, slang. They lift their tea-cups or fan themselves to date. But what of it, after our first sense of its photographic curiousness is past? In aiming at the trivial and the ephemeral they have almost surely missed better things. (HPW 119)

The 'better things' that Hardy had in mind were the underlying truths of human life, which in his view transcended the particular situations in which his characters found themselves. He wrote in his 'General Preface to the Novels and Poems' (1912) that his protagonists 'were meant to be typically and essentially those of any and every place' and should be seen as 'beings in whose hearts and minds that which is apparently local should be really universal' (HPW 46). Hardy urged his readers to differentiate between the ephemeral and the permanent in order to 'distinguish truths which are temporary from truths which are eternal, the accidental from the essential, accuracies as to custom and ceremony from accuracies as to the perennial procedure of humanity' (HPW 118). This injunction chimes with Baudelaire's claim that the artist's aim 'is to extract from fashion the poetry that resides in its historical envelope, to distil the eternal from the transitory' and that also recalls his oft-quoted claim that modernity 'is the transient, the fleeting, the contingent; it is one half of art, the other being the eternal and the immovable'. ${ }^{47}$

Hardy, however, was uneasy about some of the new tendencies in fiction. He was resistant to open-ended narratives in which indeterminacy took precedence over closure. He responded to Arthur Symons's impressionist 'slice of life' stories by suggesting that this 'modern' approach to writing would not 'displace the school of long standing because that is founded on something outside literary rules the eternal instinct of human nature to remember \& to re-tell \& muse over a tale with an ending, \& to forget the more numerous incidents of life which come to nothing' ${ }^{48}$ For Hardy, the motivated ending was a key feature of 'organic' narratives, those in which 'the principle of construction' is carried through to the conclusion of the text. ${ }^{49}$ Some of James's work seemed to Hardy to adopt this approach, leaving him to wonder 'whether they will stand as art, - the selecting reason being absent'.$^{50}$ For Hardy, the problem lay not with representations of contingency per se but with the failure to ensure that it was properly motivated in artistic terms; if artistic purpose and control were missing, little could be learned from such representations, which 
in his view simply cut human beings off from any sense of destiny (however tragic) or meaning.

Joseph Conrad's work resonates with the concerns raised by Hardy, though his most innovative novels accept indeterminacy in ways that Hardy resisted, a sign, perhaps, that they are more fully modernist in conception and realisation. Like Ford, Conrad is associated with impressionism, and Ford went to great lengths in his critical writings to position Conrad as an impressionist. Conrad's remarks about impressionism suggest that he had reservations about this designation, however. He observed of Crane's narrative method: 'He is certainly the impressionist and his temperament is curiously unique. His thought is concise, connected, never very deep - yet often startling. He is the only impressionist and only an impressionist' ${ }^{51}$ The last part of this statement is ambiguous. It can be interpreted either as an exact description of Crane's technique or as a negative judgement of its limitations. It is certain that Conrad wanted to go beyond surface truths in order to analyse underlying realities, even if he also remarked of The Red Badge of Courage (1894/1895) that in it Crane's 'impressionism of phrase went really deeper than the surface', a recognition, perhaps, that Crane was no more content with surface impressions than Conrad himself. ${ }^{52}$

Nonetheless, much of Conrad's work uses impressionist techniques (time shifts, delayed decoding, unreliable narrators, multiple viewpoints, emphasis on the visual imagination) and relies on metaphors that complicate the act of seeing. ${ }^{53}$ It was these aspects of Conrad's fiction that troubled James, who was sceptical about Conrad's technique of 'multiplying his creators', which he described as 'so special, eccentric and desperate a course, so deliberate a plunge into threatened frustration'. For James, Conrad's use of nested narrators directed too much attention to their subjective perceptions, thereby making his storytellers 'almost more numerous and quite emphatically more material than the creatures and the production itself' ${ }^{54}$ By forcing readers to ask whose viewpoint was trustworthy, Conrad's multiplied perspectives undermined the narrative itself. More was hidden and obscured by this relativism, James implied, than could possibly be revealed. Conrad's 'perversity of method - his dealing with his material by relays of reporters 3 or 4 deep, like the chain of men passing buckets of water at a fire', struck James 'as "rum" beyond all words'..$^{55}$

These are interesting objections, but they fail to see that Conrad's use of ambiguous narrators is part of a deliberate strategy, an attempt 
to evoke acts of cognition in all their precarious complexity. This strategy is inseparable from Conrad's preoccupation with problems of language and literary form, the two aspects of their shared project (the search for a new kind of novel) that Ford insisted upon in his reminiscences. Conrad suggested that he could not express himself by means of established literary modes or in conventional language. He wrote that 'it is only through complete, unswerving devotion to the perfect blending of form and substance; it is only through an unremitting never-discouraged care for the shape and ring of sentences that an approach can be made to plasticity, to colour, and that the light of magic suggestiveness may be brought to play for an evanescent instant over the commonplace surface of words: of the old, old words, worn thin, defaced by ages of careless usage' ${ }^{56}$ This recognisably modernist viewpoint insists that language and style need to be renewed if the writer is to express himself adequately. Familiar literary modes are merely 'the temporary formulas' of the writer's craft, which must give way to 'the stammerings of his conscience and to the outspoken consciousness of the difficulties of his work'. ${ }^{57}$

Difficulty lies at the heart of Conrad's modernism because the renewal of the novel - the extension of its possibilities - at his hands brought no guarantee of completion but rather called attention to the uncertain nature of his visions. As Allon White has shown, 'difficulty and obscurity become constitutive of the very being of the art work' in early modernist fiction, and the resultant opacity becomes 'a fecund source of exploratory understanding about the place and nature of subjectivity and culture'. ${ }^{8}$ Conrad saw himself as a writer capturing fugitive moments that he plucked from the temporal flux in order to reveal the inner truth of 'the rescued fragment'. Such truths were subjective and provisional. They depended on the author's personal sense of things, and they represented shards from an unrealisable whole. This meant that fiction, as Hardy had put it, was a series of seemings.

Conrad maintained that the 'aim of art' is 'obscured by mists' and that fiction could neither provide 'the clear logic of a triumphant conclusion' nor reveal 'the Laws of Nature'.$^{59} \mathrm{He}$ realised this conception of art in his major modernist novels - Heart of Darkness (1899), Lord Jim (1900), Nostromo (1904), The Secret Agent (1907), and Under Western Eyes (1911) - each of which refuses to disperse the fog, in keeping with their author's conviction that knowledge of human life is a perennially murky affair. The anonymous narrator in Heart of Darkness gives the best description of the interpretative difficulties that 
confront readers of Conrad's murky texts: 'The yarns of seamen have a direct simplicity, the whole meaning of which lies within the shell of a cracked nut. But Marlow was not typical [...] and to him the meaning of an episode was not inside like a kernel but outside, enveloping the tale which brought it out only as a glow brings out a haze, in the likeness of one of these misty halos that sometimes are made visible by the spectral illumination of moonshine' (HD 105).

But Conrad was curious about more than the obscurity of human motivation. He was interested in describing places, atmospheres, and people. He wrote in his preface to Tales of Unrest that his story 'The Return' (1898) 'consists for the most part of physical impressions; impressions of sound and sight, railway station, streets, a trotting horse, reflections in mirrors, and so on, rendered as if for their own sake' ${ }^{60}$ If we tend to emphasise the obscurities in Conrad's work, then we should also acknowledge that his desire to make his readers visualise the world leads him to give them specific impressions of particular objects and scenes. Woolf latched on to this aspect of Conrad's work when she pointed out that it was full of epiphanies in which the author 'sees people as if he had never seen them before; he expounds his vision, and we see it, too'. Woolf thought these visions were 'the best things in his books' (VW2 142). The critical attention that is directed at Conrad's obsession with obscure human motivations sometimes misses this sensory aspect of his work, which manifests itself in a painstaking attention to closely observed detail, as in this scene from Lord Jim:

There was, as I walked along, the clear sunshine, a brilliance too passionate to be consoling, the streets full of jumbled bits of colour like a damaged kaleidoscope: yellow, green, blue, dazzling white, the brown nudity of an undraped shoulder, a bullock-cart with a red canopy, a company of native infantry in a drab body with dark heads marching in dusty laced boots, a native policeman in a sombre uniform of scanty cut and belted in patent leather, $[\ldots]$ Under the shade of a lonely tree in the courtyard, the villagers connected with the assault case sat in a picturesque group, looking like a chromo-lithograph of a camp in a book of Eastern travel. ( $L J 158,159)$

Conrad's interest in material reality goes hand in hand with his philosophical concerns and his fascination with the ideas by which human beings live. John G. Peters rightly observes that "literal and figurative "seeing" are inextricably linked in Conrad's works, and his "seeing" is 
far reaching' since it comprises cognition of physical phenomena and reflection on 'the nature of human existence and the nature of western civilization' ${ }^{61}$ Interest in accuracy of vision is a key feature of much modernist theory and practice. It plays a vital role in its poetic traditions, perhaps above all in Imagism, which emerged in the years just before the First World War, though its philosophical roots lie in the nineteenth century.

Conrad's novels are concerned above all with the difficulty of seeing accurately and justly. Their main metaphors for vision systematically emphasise the partial, blurred, and unclear nature of perception. Desperate to be understood, Lord Jim's eponymous protagonist cries out to Marlow: 'Can't you see it? You must see it' (LJ 134). Marlow, however, insists throughout his narrative that he cannot visualise Jim clearly at all. His account is in a sense not about Jim but about processes of perception and judgment. Jim and the troubling events in which he has been involved allow only 'glimpses' and 'conjectures'; they remain 'obscure', 'incomprehensible', and 'misty'. In contrast to one character's simplistic claim that one 'must see things exactly as they are' (LJ 162) - an ironic allusion to Matthew Arnold's well-known claim that perfection 'can never be reached without seeing things as they really are' - Marlow maintains that he was 'fated never to see [Jim] clearly' (LJ 221) but 'was bound to him in the name of that doubt which is the inseparable part of our knowledge' (LJ 206). ${ }^{62}$ The ironies multiply here, for Arnold's dictum had been given a subjective turn by Walter Pater in The Renaissance (1873), in which the latter insisted that 'the first step towards seeing one's object as it really is, is to know one's impression as it really is' and then suggested that what mattered in this process of reflection was the personal response: 'What effect does it really produce on me?' ${ }^{63}$ By the time we get to Marlow, it has become impossible to understand what the effect on the perceiving mind actually is, with the result that the observer is lost in a sea of hazy speculations.

Conrad described his artistic aims in his preface to The Nigger of the 'Narcissus': 'My task which I am trying to achieve is, by the power of the written word to make you hear, to make you feel - it is, before all, to make you see. That - and no more, and it is everything'. ${ }^{64}$ This description has often been quoted, but no less important is the qualification that Conrad provides when he goes on to explain that 'the aim of art [...] is inspiring, difficult - obscured by mists' and to suggest that it 'is not in the clear logic of a triumphant conclusion' ${ }^{65}$ 
For Conrad, then, to make readers see is to encourage them to accept that partial insight is the best that can be achieved and to draw attention to the uncertain nature of perception. Conrad's aim, according to Ian Watt, was 'not so much "to make us see," as " "to make us see what we see" - a characteristically modernist concern. ${ }^{66}$

Conrad, furthermore, was troubled by the discrepancy between surface phenomena (as they are apprehended by the senses) and an underlying reality that is less easily discernible. As with Hardy, there is an urge here to go beyond the particular in order to discover more essential truths. Art, Conrad writes, 'may be defined as a single-minded attempt to render the highest kind of justice to the visible universe, by bringing to light the truth, manifold and one, underlying its every aspect'. If the first part of this formulation emphasises what can be observed by the eye, then the second part enjoins the writer to expose the noumenal reality that underpins the perceptible world. Like Baudelaire and Hardy, Conrad seeks to differentiate the permanent and the universal from the ephemeral and the particular. Art is 'an attempt to find in its forms, in its colours, in its light, in its shadows, in the aspects of matter, and in the facts of life what of each is fundamental, what is enduring and essential'. ${ }^{67}$

It is no accident, then, that in Lord Jim, Marlow sees Jim as a representative figure, whose predicament has implications for humanity's understanding of itself and the belief systems by which it abides. Marlow's desire to redeem Jim's behaviour is motivated by his need to combat 'the uneasy doubt uprising like a mist, secret and gnawing like a worm, and more chilling than the certitude of death - the doubt of the sovereign power enthroned in a fixed standard of conduct' ( $L J 80$ ) - because he fears the consequences of accepting that the idea of an ethical code to which all individuals should give their assent has no metaphysical foundation. If we return to the preface to The Nigger of the 'Narcissus' with these preoccupations in mind, we can see that Conrad's recognition of the subjective nature of the artist's vision and the reader's response to it leads him to address the problem of solipsism and the danger of moral chaos through an appeal to the idea of community. The artist's vision appeals to a complex of shared emotions that, Conrad suggests, offers human beings who are isolated from each other the chance of discovering an 'invincible conviction of solidarity that knits together the loneliness of innumerable hearts' and 'binds together all humanity - the dead to the living and the living to the unborn'. ${ }^{68}$ 
But the most cursory reading of Conrad's work reveals that this belief in solidarity cannot withstand the numerous pressures to which it is subjected, and this is why his novels explore such themes as human isolation, psychological breakdown, political and economic exploitation, the opacity of other people, the limits of community, and the meaninglessness of life in a mechanical universe. There are close parallels between Hardy and Conrad in this respect. If the former repeatedly denied that he was a pessimist, then his view of things was hardly cheerful: 'The more we know of the laws \& nature of the Universe the more ghastly a business we perceive it all to be $-\&$ the non-necessity of it. [...] that the world exists is a fact absolutely logicless \& senseless ${ }^{6}{ }^{69}$ Conrad, in turn, imagined the universe as an appalling machine that has 'evolved itself $[\ldots]$ out of a chaos of scraps of iron' to no purpose whatever: 'The most withering thought is that the infamous thing has made itself; made itself without thought, without conscience, without foresight, without eyes, without heart'. ${ }^{70}$ Marlow expresses this view in Heart of Darkness when he describes existence as 'that mysterious arrangement of merciless logic for a futile purpose' (HD 178), which at best allows the individual to live without illusions.

Conrad's novels are characterised by acerbic irony and glum prognostication. His fictional worlds are peopled by monstrous egotists, impractical idealists, and intransigent fanatics whose various schemes are subjected to sardonic scrutiny. His major texts are studies of defeat. Their protagonists end up discredited, ruined, or dead, while their dreams of personal glory or social melioration lie in tatters around them. In Conrad's writing, human endeavour and the rationalisations that justify it are treated with corrosive scepticism. The following exchange from Nostromo is symptomatic:

'Upon my word, doctor, things seem to be worth nothing by what they are in themselves. I begin to believe that the only solid thing about them is the spiritual value which everyone discovers in their own form of activity -'

'Bah!' interrupted the doctor, without stopping for an instant the idle swinging movement of his legs. 'Self-flattery. Food for that vanity which makes the world go round'. (N 266)

For Conrad, the justifications conjured up by individuals to give meaning to their actions are private myths that have no purchase on reality. What comes across most strongly in Conrad's work is his lack 
of faith in all systems of belief, political structures, and human beings. Nietzsche's suggestion that nihilism was the diagnosis par excellence of the modern condition speaks to Conrad's despair: 'Together with the fear of man we have also lost our love of him, our reverence for him, our hopes for him, even the will to him. The sight of man now makes us weary - what is nihilism today if it is not that? - We are weary of man'. ${ }^{71}$

Conrad's scepticism is inseparable from his conviction that consciousness is an intolerable burden. As Marlow puts it in Lord Jim: 'Hang ideas! They are tramps, vagabonds, knocking at the back-door of your mind, each taking a little of your substance, each carrying away some crumb of that belief in a few simple notions you must cling to if you want to live decently and would like to die easy!' ( $L J 75)$. His most troubled protagonists are characterised by a heightened awareness of their flaws and of the weaknesses in their societies' most cherished beliefs. Whereas in Henry James's novels the work performed by the refined consciousness is presented as a valuable augmentation of experience, in Conrad's fiction it is typically a cause of further suffering and, at times, the source of terror. What Matthew Arnold, trying to understand the inner nature of modernity, referred to as the 'dialogue of the mind with itself' becomes in Conrad's work a form of hyperreflexivity that results in scepticism, psychosis, and suicide. ${ }^{72}$ For such figures as Kurtz and Decoud, self-knowledge brings despair and death. Kurtz, we are told, is a man whose intelligence is focused 'upon himself with horrible intensity' ( $H D$ 144), and this solipsistic introspection has tragic consequences: ' $[\mathrm{H}]$ is soul was mad. Being alone in the wilderness, it had looked within itself, and, by heavens! I tell you, it had gone mad' (HD 144). Decoud in his solitude confronts his fundamental lack 'of faith in himself and others' (HD 408). Abandoned to the vastness of nature, he loses 'all belief in the reality of his action past and to come' and begins to see 'the universe as a succession of incomprehensible images' (HD 409). Kurtz is provoked to madness by an audit of his psyche, while Decoud is driven to suicide by an inspection of external reality, but the result is the same in both cases: a witheringly nihilistic view of self and world.

In James's late work, the subtleties of the narrative depend on the presence of focalisers who are intelligent and perceptive. They are also given the time, in novels that proceed at a leisurely pace, to reflect on their experiences and to mull over their implications (as, for example, when Isabel Archer comes to terms with Gilbert Osmond's character 
in The Portrait of a Lady, or when Lambert Strether grasps the true nature of Chad's relationship with Madame de Vionnet in The Ambassadors). But Conrad is more interested in the problem of clear thought at moments of intense pressure. There is a divergence in his writing between impressionism as a literary technique and impressionism as a means of cognition that enables individuals to live.

This split is very much the subject of Lord Jim, a novel that explores the limitations of Stoicism's faith in humans' capacity to use reason to "make considered choices among "impressions" or "appearances", meaning anything that comes within range of our senses, together with whatever thoughts and feelings these sensations evoke'. ${ }^{73}$ Of relevance to Jim, given his dilemma on the Patna, is the following injunction from Epictetus's Discourses: 'Don't let the force of the impression when first it hits you knock you off your feet; just say to it, "Hold on a moment; let me see who you are and what you represent. Let me put you to the test." "74 But when Jim is confronted by events that unfold with great rapidity, he is unable to consider his actions in this way. Marlow does not exonerate Jim, but he takes seriously his claim that he acted unthinkingly because he 'was crowded with a tumult of events and sensations which beat about him like the sea upon a rock' ( $L J$ 122-123), leaving him to feel that he 'had suffered himself to be handled by the infernal powers who had selected him for the victim of their practical joke' ( $L J 123$ ). Hence Jim's claim that when he leapt off the Patna he had been unaware of what he was doing and 'knew nothing about it till [he] looked up' ( $L J 125)$.

Marlow is sceptical about this defence and distances himself from Jim's attempts to exculpate himself. He sees Jim's passivity as a 'strange illusion' ( $L J 123$ ) but is unwilling to judge Jim's actions. This is because Marlow has 'enough confidential information about [him]self to harrow [his] own soul till the end of [his] appointed time' (LJ 68). Viewing Jim both as a scapegoat for the wider community and as a symbolic figure, Marlow concludes that it was 'as if the obscure truth involved were momentous enough to affect mankind's conception of itself' ( $L J 112$ ). The obscure truth, it seems, is bound up with the role that egoism plays in human life, since Jim's efforts to redeem himself are motivated not by a desire to make reparation but to recover his masculine self-esteem. Lord Jim thus engages with the problematic nature of a culturally conditioned male identity that is based on heroic ideals and imperialist values. ${ }^{75}$ Marlow implies that Jim cannot be judged partly on ethical grounds (he cannot know if he would have 
acted differently) and partly for political reasons (Jim is the product of a society whose imperial commitments and gender attitudes are questionable). There is also the vexing problem of language, the sheer difficulty of describing events, which leads Marlow to alert his readers to the gap between a visualised scene and its rendition in words: 'I am trying to interpret for you into slow speech the instantaneous effect of visual impressions' ( $L J 78$ ).

Jim therefore remains a problem that cannot be solved. His character is impenetrable, and his actions are inexplicable. Nor is Stein's ambiguous metaphor for humanity's existential plight much help. Stein seems to suggest that the dilemma consists in the need to reconcile the reality principle with the demands of the imagination. In order to cope with this irresolvable conflict, the individual must submit to 'the destructive element' - the unpredictable, contingent, and arbitrary experience of a life that is beyond anyone's power to control. This perspective aligns Stein with the Stoicism that is questioned in the novel, since it instructs individuals to embrace whatever fate befalls them rather than to fight to change it. But whereas in Epictetus's thought the natural order is seen as fundamentally harmonic and benevolent - which means that it makes sense for human beings, for all the vicissitudes they suffer, to try to live in accordance with it - in Stein's conception of reality there is a rift between the order he discerns in nature and the tumult that characterises human life. The destructive element designates a harsh, unforgiving ontology that grounds Conrad's modernist scepticism.

\section{Debating Imperialism}

Conrad's scepticism might be described as a kind of proto-existentialism, so uncompromising is its stark view of reality, and Conrad, of course, was capable of suggesting that ethics had no place in an absurd universe. ${ }^{76}$ A different kind of scepticism, though it could be equally severe, is visible in a number of modernist works that address themselves to the problem of imperialism, a troubling and much-debated issue in late nineteenthand early twentieth-century England. It was impossible at the turn of the century to be unaware of imperialism, for it was present in the very fabric of the nation's life. Imperialism's meanings, viability, and justness were debated in the press, in critical books and articles, in parliament, and in literature. Material artefacts associated with it were everywhere visible. These included art objects displayed in museums and private homes, 
items of trade that ranged from consumables through to products that were indispensable to the development of an increasingly technologised capitalist economy, and public sculptures and civic buildings that were designed to assert Britain's international power and prestige. Imperialism was at the heart of the education system and gave rise to the production of a wide range of juvenile literature that presented it as a heroic and altruistic civilising enterprise, which aimed to bring God, law, and order to supposedly 'primitive' peoples who needed to be saved from savagery and barbarism. ${ }^{77}$ And it played a huge role in elaborate public displays like Queen Victoria's Diamond Jubilee (1897), which lasted for over two weeks, involved representatives from all parts of the Empire, and was commemorated by the Poet Laureate (Alfred Austin) in the heartily imperialist poem 'Victoria'.

In the hands of modernist writers, the representation of empire was characterised by ambiguities and ambivalences. This is partly because by the early twentieth century imperialism had lost much of its former lustre. It had always had its critics, of course, but at the turn of the century an influential group of new Liberals (J. L. Hammond, L. T. Hobhouse, John Hobson, and C. F. G. Masterman) sought to demystify and demythologise it by explaining it in terms of domestic underconsumption and the aggressive search for new markets. ${ }^{78}$ Hobson, for example, maintained that imperialism was an 'evil business' that was 'in large measure resolvable into capitalist or profit-seeking influences' ${ }^{79}$ In addition to these cogent criticisms, there was a good deal of opposition to the Boer War of 1899 to 1902 . Thereafter, the idea of imperialism 'suffered a contraction, a loss of moral content, from which it never completely recovered'. ${ }^{80}$ Patrick Brantlinger thus suggests that by the end of the Victorian period there was a widespread feeling of 'defensiveness, self-doubt, and worries about "fitness," "national efficiency," and racial and cultural decadence' ${ }^{81}$

The relationship between modernism and imperialism is a complex one, not least because modernism to some extent emerged from within (and to varying degrees in opposition to) the imperialist project. It is easy to identify various works that dealt with it to a greater or lesser extent, but harder to draw conclusions either about their treatment of it or about the effect it had on their fragmented forms. Some critics suggest that modernism needs to be understood as both a reaction to, and a product of, the multiple legacies of imperialism and colonialism. Simon Gikandi, for example, argues that modernism in England 'was generated by a crisis of belief in the efficacy of colonialism, its culture, 
and its dominant terms', while Timothy Brennan suggests that it was forged "within a structure of interactive, cross-cultural contacts that combined an aesthetic of "primitive art," on the one hand, with political uneasiness toward a colonial system, on the other'. ${ }^{82}$ In such accounts, modernism responds to a sense of crisis that is generated by anxiety about the putative superiority of English and European civilisation to that of the regions and countries that imperialism had annexed. For Edward W. Said, in an influential account, modernism registers 'the disturbing appearance in Europe of various Others, whose provenance was the imperial domain'. ${ }^{83}$ Said reads modernism as a reaction not just to imperialism but to the racial and cultural differences that it brought into view, and he suggests that these disturbing differences were not only articulated as new subject matter but also communicated through form. Modernists disclosed 'an extreme, unsettling anxiety' about imperialism, and their technical innovations were 'a response to the external pressures' it exerted on European values. ${ }^{84}$ The fragmentation of subjectivity that is a marked feature of modernist writing occurs in part because long-held assumptions about racial hierarchies collapse, to be replaced by a burgeoning awareness that subjectivity is culturally constructed and open to contestation.

Important questions arise here. How is the relationship between imperialism and modernism to be understood? Is modernism conceivable outside the context of imperialism, which for some critics is the main cause of its emergence, or is it rather an already existing movement that then addresses the question of imperialism from a distanced perspective? Is modernism complicit in imperialism's racist assumptions, or is it an oppositional set of practices that call such prejudices into question? Is it both together, either at different times and in different texts or simultaneously within internally fissured works? Michael Bell claims that modernism offered 'a diagnostic understanding of the colonial mentality', a view that positions it as a critical and interrogative textuality rather than a defensive or compliant one. ${ }^{85}$ Fredric Jameson, in contrast, sees imperialism as a cultural unconscious that could not be known but that nonetheless manifested itself in modernism's 'inner forms and structures'; for Jameson, 'no intensity of self-examination' or 'scientific deductions on the basis of the internal evidence of First World data, can ever be enough to include this radical otherness of colonial life, colonial suffering, and exploitation'. ${ }^{86} \mathrm{He}$ concludes that 'traces of imperialism' can be discerned in European modernism not 'in content or in representation' but 'as formal symptoms, within the structure of First World modernist texts' ${ }^{87}$ 
These contrasting views are unlikely to be resolved satisfactorily. Evidence can be adduced to support both sides of the debate, while interpretations of texts and their formal strategies are always provisional. But it is incontrovertible not only that modernism responded to imperialism in a range of ways, which we should resist theorising in a totalising fashion, but also that several modernists explicitly engaged with imperialism and attempted to 'know' it and to address its implications quite consciously. As Ford, an inveterate opponent of imperialism, observed of the Boer War: 'During that rather disagreeable period I made one or two speeches in the interests neither of Boer nor of Englishman, but of the African natives. To them it seemed to me - and it still seems so - the African continent belongs'. ${ }^{88}$ At a minimum, some modernist texts registered - in different ways and with different political agendas - the problem of imperialism, often emphasising its injustice. In doing so, they pointed to the instability of racial conceptions of identity (which typically underpinned the imperialist project) with far-reaching consequences for its understandings of subjectivity and agency. Paul Gilroy helpfully suggests that modernity might be thought to begin 'in the constitutive relationships with outsiders that both found and temper a self-conscious sense of Western civilisation' ${ }^{99}$ This self-consciousness figures prominently in modernism's engagements with imperialism's legacies, in which it is sometimes presented as a gain in cultural understanding and sometimes as a debilitating loss of faith in such value-laden concepts as 'Europe', 'Western society', and 'the white man's burden'.

Conrad's fiction is centrally concerned with imperialism. His first two novels - Almayer's Folly (1895) and An Outcast of the Islands (1896) - focus on the clash of cultures in the Malaysian archipelago. These works are late imperial romances that question the myth of the "civilizing mission or "development" and relate in its stead a counterromance of descent into realms of stubborn strangeness and enchantment'.$^{90}$ It was the exotic nature of the societies depicted in these texts that attracted Conrad's first readers. But Conrad was questioning common assumptions about race and culture. In his 'Author's Note' to Almayer's Folly, he justified his novel against the charge that it was 'decivilized', arguing that this accusation was aimed in part at 'the strange people and the far-off countries' with which it dealt and which are 'condemned in a verdict of contemptuous dislike'.$^{91}$ Such judgments were unjust because they ignorantly assumed 'that in those distant lands all joy is a yell and a war dance, all pathos is a howl and a 
ghastly grin of filed teeth, and that the solution of all problems is found in the barrel of a revolver or on the point of an assegai'. ${ }^{92}$ This was a challenge to imperialist stereotypes and their cultural preconceptions. There was, Conrad insisted, 'a bond between us and that humanity so far away', which inclined him 'to sympathize with common mortals, no matter where they live' ${ }^{93}$

Almayer's Folly touches on the issues that Conrad addresses in greater detail in Heart of Darkness. It is also caught up in the same problematic. For inasmuch as Conrad's novels criticise European attitudes and behaviour, they nonetheless rely on essentialist conceptions of the 'savage' and the 'civilised', which persistently infiltrate his work. What complicates this judgment, of course, is that the views expressed in his fiction are not straightforwardly attributable to their author because they are either rendered by means of free indirect discourse or expressed by narrators whose authority is in question. So when Marlow in Heart of Darkness presents the Congolese in the terms that Conrad had mocked in his 'Author's Note' to Almayer's Folly, we cannot assume that his racism is shared by his creator. That said, Heart of Darkness is complicit in Victorian ethnographic assumptions despite its scathing portrayal of imperialism in the Belgian Congo. To phrase it like this is to highlight one among the novel's many ambiguities. Heart of Darkness is an exposé of abuses perpetrated in the Belgian Congo, and Marlow informs his auditors that 'one knows that some real work is done' (HD 110) wherever the British are in command. But this claim sits uneasily with his opening words, uttered in the Thames estuary - " "And this also $[\ldots]$ has been one of the dark places of the earth"' (HD 105) - and with the novel's closing image of generalised darkness descending upon the narrator and his friends. Edward Said observes that by disclosing imperialism's delusions, violence, and waste, Conrad 'permits his later readers to imagine something other than an Africa carved up into dozens of European colonies, even if, for his own part, he had little notion of what that Africa might be'. ${ }^{94}$

The London setting is important because the British capital was the beating heart of its empire. As T. H. S. Escott put it in the 1880s: 'London has become increasingly the metropolis of the empire, and a minute and far-reaching system of bureaucratic control is exercised from Whitehall'. ${ }^{55}$ Jonathan Schneer has shown that imperialism 'was central to the city's character in 1900, apparent in its workplaces, its venues of entertainment, its physical geography, its very skyline; apparent, too, in the attitudes of Londoners themselves'. ${ }^{96}$ Heart of 
Darkness both distances its critique of imperialism from Britain and at the same time brings it home; by setting the telling of the story at a London dock, Conrad invites his readers to ask if the horrific events being recounted only take place in those parts of the empire that are run by dodgy foreigners. Conrad implies that if the whole of Europe is responsible for Kurtz, then Britain (however complex and vexed its relationship to Europe), cannot deny all responsibility for him, cannot somehow set itself apart either from the predicament in which he finds himself or from his reprehensible actions. And imperialism, wherever it occurs, is seen as a dubious enterprise throughout Heart of Darkness. Marlow drily observes that the "conquest of the earth, which mostly means the taking it away from those who have a different complexion and slightly flatter noses, is not a pretty thing when you look into it too much' (HD 69). And if he suggests that conquest may be redeemed by an 'idea' of some sort, then his subsequent narrative debunks all the ideas that are offered as positive rationales for the imperialist project. In any case, an 'idea' for Marlow is a disturbing fetish, 'something you can set up and bow down before, and offer a sacrifice to' (HD 70), a logic that is enacted in the most literal way imaginable by Kurtz.

The assumptions that informed imperialism depended on a complex of ideas about racial superiority, the difference between the 'primitive' and the 'civilised', the need to Christianise 'heathen' peoples, the benefits of trade, and the right of the strong to exploit the weak. When such assumptions become untenable, it is not only the subject matter of novels that changes but also the terms in which that subject matter is treated. Language, style, and literary form fracture under the pressure of dealing with realisations that undermine a dominant society's tacitly accepted beliefs. Heart of Darkness registers this pressure not only through its concern with discourse and narrative structure but also through its engagement with issues of audience and readership. For the problem that Conrad faces is that of conveying to his readers the true nature of the experiences Marlow is describing. The difficulty of understanding what has happened to Kurtz is at stake here, but so too is the discrepancy between colonialist rhetoric and its reality. This involves Marlow in a double problem: firstly, his auditors are members of a ruling elite who have no inkling of what he is trying to tell them; secondly, they may be so rooted in the 'civilization' whose ideologies he is challenging that they will not be able to see how corrupt it is. ${ }^{97}$ Heart of Darkness thus persistently highlights problems of articulation, communication, understanding, and reception. 
Conrad's writing also explores how technology alters human beings and shows how difficult it is to resist its burgeoning power. Texts like Heart of Darkness, Lord Jim, and Nostromo register the involuted relationships between commerce, capitalism, and technology, seeing these as central to the process of globalisation. ${ }^{98}$ In Heart of Darkness, the company on whose behalf Marlow goes to the Congo is 'a Continental concern' (HD 108) engaged in a 'merry dance of death and trade' (HD 115), while in Nostromo economic and political life is directed by American capital. Conrad recognises that a combination of technological power and financial muscle gives Europe and America power over the places in which they do business. The metaphor of hollowness permeates Heart of Darkness, while the phrase 'material interests' sums up the remorseless energy of capital in Nostromo. But both texts also explore how these forms of power transform subjectivity, how they alter individuals who are products of the systems in which they live and work. Colonialism, Laura Chrisman observes, is in Heart of Darkness shown to be 'a constitutive element of metropolitan subjectivity'. ${ }^{99}$ As Marlow is informed: 'The changes take place inside' (HD 112).

Except that they do not take place only inside. Both Heart of Darkness and Nostromo attend to the connections between material change and its effects on bodies as well as minds. When Marlow approaches the first Company station in Heart of Darkness, he stumbles into a grove of death where the Congolese natives - either 'raw matter' ( $H D$ 117) to be put to work or 'inefficient' rejects, 'black shadows of disease and starvation' (HD 118) - have been left to rot and die. The novel's critique of colonialism cannot disguise the hierarchical assumptions that inform Marlow's responses to the natives he encounters. These responses combine positive reactions to their alleged natural vitality with a sense of disturbance at the changes enforced upon them by a colonising process that turns them into instruments of European commerce. The text's doubled response to this process is both demeaning and sympathetic. If Marlow's fireman is described as 'a dog in a parody of breeches and a feather hat, walking on his hind-legs' who should be 'clapping his hands and stamping his feet on the bank' ( $H D$ 140), he is also depicted as an exploited figure who has been forcibly removed from his normal environment and made to work as an 'instrument' (HD 156) on a steamship.

But Marlow's attitude to the exploited and abused natives falls far short of treating them as human equals; indeed, he refers casually to the loss of the life of 'a savage who was no more account than a grain 
of sand in a black Sahara' (HD 156). John A. McClure rightly argues that texts like Heart of Darkness are anti-imperial 'in their repudiation of the West's self-image as a heroic agent of global civilization' but also 'perpetuate a Western tradition of "othering" the subjects of imperialism and repudiate all attempts on the part of these subjects to assimilate "Western" ways'. ${ }^{100}$ In Heart of Darkness, colonialism is shown to be complicit in violent exploitation and embroiled in exporting it, but this does not mean that the novel frees itself of primitivist assumptions, any more than it renounces a gender politics that positions European women as the carriers of illusions about public life and keeps them in a subaltern position: 'They - the women I mean - are out of it - should be out of it. We must help them to stay in that beautiful world of their own, lest ours gets worse' (HD 153).

Nostromo is no less aware of the significance of the material changes that transform communities. Early in the novel, the San Tomé mine's effect on the landscape is registered: 'The waterfall existed no longer. The tree-ferns that had luxuriated in its spray had dried around the dried-up pool, and the high ravine was only a big trench half filled up with the refuse of excavations and tailings. The torrent, dammed up above, sent its water rushing along the open flumes of scooped tree trunks striding on trestle-legs to the turbines working the stamps on the lower plateau' ( N98). A process of modernisation has been started that cannot be slowed or halted; in time it will introduce the 'material apparatus of perfected civilization which obliterates the individuality of old towns under the stereotyped conveniences of modern life' (N90). Stereotyping implies standardisation - of houses, towns, countries, people, and ways of life.

This is a key modernist anxiety, which features prominently in the work of such writers as Ford, Lawrence, and Lewis. Conrad is no less troubled by the ways in which an instrumental logic orientated to productivity turns individuals into relay points in the systems they serve. Thus the accountant in Heart of Darkness is bothered by the groans of the dying solely because they disturb his concentration and might lead him to make 'clerical errors' (HD 120); the station manager deplores Kurtz's 'methods' only because they have 'ruined the district' (HD 164) for trade; the chief engineer in Nostromo sees Sulaco as nothing more than an opportunity for technology to develop itself - it is 'a railway station, a terminus, workshops, a great accumulation of stores' ( $N$ 258). Those who celebrate the technological drive are subjected to Conrad's sharpest irony. The French representative of 
'a syndicate of European capitalists' ( $N$ 166) falls 'prey to a screaming ecstasy' at the thought of 'Ten million dollars' worth of copper practically in sight $[\ldots]$ Ten millions in sight! And a railway coming - a railway! They will never believe my report. C'est trop beau' (N 172).

Conrad's is a far-reaching political diagnosis, and he offers a penetrating account of modernity's unleashing of economic and technological forces that swiftly took on an impetus of their own. Nostromo's Gould professes the belief that 'law, good faith, order, security' will be established once 'material interests [...] get a firm footing' because 'they are bound to impose the conditions on which alone they can continue to exist' ( $N$ 81). According to this view, capitalism confers social benefits for no reason other than that they enable it to pursue its course more smoothly. The only 'ray of hope' Gould can offer is that a 'better justice will come afterwards' (N 81). Nostromo calls this belief into question. Sulaco is shown to be the economic periphery of an industrial and imperial centre that develops according to its own expansionist logic, which means that 'the great silver and iron interests shall survive, and some day shall get hold of Costaguana along with the rest of the world' ( $N$ 79-80). In Monygham's terms, material interests cannot and will not let anything 'jeopardize their development' (N418). The San Tomé mine, the novel's symbol of capitalist endeavour, hangs 'over the whole land, feared, hated, wealthy; more soulless than any tyrant, more pitiless and autocratic than the worst Government; ready to crush innumerable lives in the expansion of its greatness' ( N 427-428). In both Heart of Darkness and Nostromo, the uncontrollable and amoral drive of an imperialist economy not only destroys indigenous social structures but also transforms the colonisers and the colonised. In doing so, both texts track the far-reaching ways in which modern identity is altered by processes that diminish human agency and erode individuals' sense of responsibility for the practices in which they are involved.

The systematic nature of the various kinds of exploitation that Conrad tracks was hidden by the rhetorics that presented capitalism and imperialism as economically and morally beneficent. It is for this reason that in Heart of Darkness, Marlow persistently draws attention not only to the unconscious attitudes of his auditors (and by implication of Conrad's contemporary readers) but also to the discrepancy between professional discourses (administrative, economic, and legal) and the reality they obscure. Conrad's letters from the 1890s suggest that 'colonialism meant an obligation to rethink traditional modes of 
realistic depiction' ${ }^{101} \mathrm{He}$ could not write about it as though it were an 'event' like any other but was compelled to rethink literary representation itself. Heart of Darkness draws attention to Conrad's suspicion of language in all its forms, including that of its own narrative procedures. The nightmarish atmosphere through which Marlow's experiences in the Congo are mediated is a key feature of the novel's linguistic self-reflexiveness. By using the imagery of darkness and fog and spectral light, the text registers its uneasiness about the European presence in Africa.

At the same time, irony is deployed to challenge imperialists' self-justifying or thoughtless rhetoric, from the starched accountant's claim that 'everything here $[\ldots]$ is very satisfactory' (HD 120), to the station manager's belief that Kurtz's actions only have a bearing on trade, and to Marlow's accusatory admission that he is 'part of the great cause of these high and just proceedings' (HD 117). The bitterest irony is reserved for the twisting of language by those who hide the truth of what they are doing in the Congo. Facing the severed heads in Kurtz's compound, Marlow comments: 'Rebels! What would be the next definition I was to hear? There had been enemies, criminals, workers and these were rebels' (HD 165). To define the Congolese as 'enemies' or 'rebels' or 'criminals' is to label them in quasi-legal terms and to subject them to a judicial power that is shown to be arbitrary and unjust. Heart of Darkness depicts the process by which European colonisers exert this linguistic-judicial control and also undermines its claims by inverting the perspective from which it is viewed. When Marlow spots a shackled chain gang, for example, he reflects that they are 'called criminals, and the outraged law [...] had come to them, an insoluble mystery from over the sea' (HD 117), and when he considers the hunger his native crew must be feeling, he observes that 'as long as there was a piece of paper written over in accordance with some farcical law or other made down the river, it didn't enter anybody's head to trouble how they would live' (HD 144).

Kurtz, of course, is the figure who is most closely associated with deceitful language. To Marlow, he is connected with speech. When Marlow fears that Kurtz has been killed, his first reflection is that he will not be able to converse with a man who 'presented himself as a voice' and whose pre-eminent quality, which 'carried with it a sense of real presence, was his ability to talk, his words - the gift of expression' (HD 152). Kurtz does not enter the novel until it is almost finished, but its preceding pages have already established the unreliability of 
European rhetoric. In short, Kurtz's 'gift of expression' is compromised from the outset. Associated with a questionable 'eloquence', Kurtz is a man who 'could get himself to believe anything' (HD 181). If the whole of 'Europe contributed to the making of Kurtz' (HD 154), then the hollowness of his eloquence would seem to disclose the moral vacuity of its imperial project, which is exposed as a beguiling myth and a cynical subterfuge. If the degenerate traders who stalk the novel are symbols of 'a flabby, pretending, weak-eyed devil of a rapacious and pitiless folly' (HD 117) who seek to 'tear treasure out of the bowels of the land $[\ldots]$ with no more moral purpose at the back of it than there is in burglars breaking into a safe' (HD 133), then Kurtz is the most rapacious coloniser of all. Kurtz's bluntly announced demise - “"Mistah Kurtz - he dead"' (HD 178) - renders eloquent but duplicitous speech unviable, leading Marlow to reflect on its significance: 'The voice was gone. What else had been there?' (HD 178). On one level, the answer is 'nothing', and read in this way the text leaves Kurtz's empty rhetoric to be displaced by a stumbling narrative that presents itself as 'the speech that cannot be silenced' (HD 140). No less hauntingly, however, Heart of Darkness simultaneously raises the question of whether Kurtz's hollowness might not be 'nothing' after all but might rather exemplify a form of (imperialist) voraciousness and brutality.

Heart of Darkness unfolds its narrative according to a linear chronology but sees London at the turn of the century as temporally contiguous with the dawn of ages. Nostromo eschews this overlapping view of temporal and metaphysical zones in favour of a cyclical view of history. The narrative is also fragmented by time shifts, alternative interpretations of events, marginalisation of characters, and destabilisation of perspective. Nostromo's preoccupation with different angles of vision is signalled in an early scene when Giorgio Viola, trying to observe a skirmish, cannot 'take in all its details at once' ( $N$ 35). This moment functions as a metonym for the novel as a whole, signalling its preoccupation with the difficulty of providing a totalising account of society. But just as Heart of Darkness is drawn to a metaphysical understanding of the human condition, so Nostromo is drawn to an alternative explanatory framework: historical determinism. The novel's political pessimism lies in its cyclical view of history, which suggests that human life inevitably follows the path of an arc, moving from stasis to revolt, then back again, in an interminable round.

Above all, Nostromo is preoccupied with the ambiguous impact of modernisation on a largely pre-industrial society. But it is a curious 
political novel. Inasmuch as it focuses on the impact of capitalist investment on Costaguana, it has little to say about the resulting transformation of its citizens' lives. Apart from some general comments on this theme, there is little of the kind of analysis Lawrence provides in Women in Love of how the running of a modern mine might affect those who work in it. We are offered a brief reference to the mine's despoliation of the landscape, but the novel's peasants and workers are conspicuous by their absence from the novel, which concerns itself with the affairs of investors, businessmen, industrialists, and political intriguers. Nostromo is also generically unstable. Its predominantly naturalistic account of how capitalism transforms Costaguana is overlaid by an allegorical narrative in which silver is treated symbolically as the source of personal corruption. The novel is in this respect a cautionary tale, but its emphasis on individual venality sits uneasily with its sociologically 'thick' account of historical change. Nostromo, crucially, works on a number of levels and incorporates different (contradictory) explanatory schema, and its concern with universal human fallibility, on the one hand, and the particularities of Central American politics, on the other, points both to Conrad's pessimistic view of human nature and to his modernist scepticism about totalising accounts of political processes.

Nostromo offers a powerful critique of capitalist modernisation, suggesting that it is impelled by an expansionism that is economic, not moral or political, and showing how precarious civic order is when a society's citizens are enthralled by material interests. Capitalism is the single greatest force in Costaguana and its main agent of historical change. It is for this reason that the titular character is such a negligible figure. Nostromo is a bit-part actor who is absent from whole swathes of the text that bears his name. His name, moreover, designates a role; a version of the Italian 'nostro uomo', it describes this character's function as a servant of the ruling class. By thus undermining Nostromo's identity, the text suggests that he is at the mercy of impersonal forces that render him insignificant. He is a cipher, a blank subject who exists because he serves interests for which he is an instrument to be used. The further point here is that he is contrasted ironically with Viola, his surrogate father. A republican follower of Garibaldi, Viola is a committed democrat who thinks Costaguana's would-be insurgents are 'not a people striving for justice' but 'scoundrels and leperos, who did not know the meaning of the word "liberty" ( N 30). Viola implies not only that Nostromo, who is interested solely in his personal 
prestige, is an apolitical pawn but also that the revolutions which stud Costaguana's history are debased versions of what the struggle for democracy should really be about. That struggle is consigned to a past that in this novel can return only as a degrading and farcical spectacle.

The novel's deployment of the time shift and proleptic irony contributes to its depiction of history as a cyclical process. The cartoonish Mitchell, with his naive faith in progress, is ridiculed for his belief that he can identify the motor of history; he displays 'a strange ignorance of the real forces at work around him' ( N 121), and anyone subjected to his whiggish views listens to him 'like a tired child to a fairy tale' ( $N$ $400)$. Conrad's use of the time shift further undermines this progressivist liberalism. Ribiera's optimistic speech about the future of Costaguana - with its 'simple watch-words of honesty, peace, respect for law, political good faith' ( $N 109$ ) - is given seventy pages after he has been shown fleeing for his life during a civil war that, in terms of the novel's chronology, occurs eighteen months later. The reader is thus aware that political events have already put paid to Ribiera's dreams of social order and national welfare. Revealingly, the novel ends with intimations of yet another turn in the cycle when it is suggested that 'the people, prevented from their aspirations' may soon 'rise and claim their share of the wealth and their share of the power' $(N 418)$ that is still being denied to them.

Nostromo is clear-sighted about the costs exacted by capitalism, especially with respect to the colonisation of land, the destruction of natural habitats, the erosion of established customs, the exploitation of indigenous peoples, and the power of foreign financiers. By describing these things, the novel extends a degree of sympathy to the antiRibierists who proclaim that the dictator - the 'creature' $(N 44)$ of the Anglo-Spanish elite and their vested interests - has 'plotted to deliver his country, bound hand and foot, for a prey to foreign speculators' ( $N$ 129). But what the novel refuses to do is to treat seriously those who make this accusation. If it can accept that they have legitimate cause for complaint, then it cannot legitimise that complaint by allowing them to articulate it in terms that would be comprehensible to rational human beings. Nowhere is this more clear than in its depiction of Pedro Montero and his men. The latter are described as 'an armed mob', a 'rabble', and a 'torrent of rubbish' (N318); barely a military force, they are rather a motley crew 'of all colours, complexions, types, and states of raggedness' ( $N$ 318). Montero, in turn, has 'an ape-like faculty for imitating all the outward signs of refinement and distinction', but his 
actions are 'determined by motives so improbable in themselves as to escape the penetration of a rational person' (N 320).

This is atavism writ large. It is also of a piece with Conrad's political scepticism. Nostromo exemplifies Marx's adaptation of Hegel's words in the Eighteenth Brumaire of Louis Bonaparte (1852) - 'all great historic facts and personages recur twice. He forgot to add: "Once as tragedy, and again as farce" - for it adopts a cyclical view of history that also draws on the idea of the downward spiral, suggesting that each cycle is a more degraded version of the one that preceded it. ${ }^{102}$ If Nostromo, the 'man of the people', is a debased version of the republican Viola, then Montero is a farcical copy of the Duc de Morny 'taught by his European experience', he intends simply 'to acquire a serious fortune for himself' ( N 321). This, in the end, is what politics is reduced to. Capitalism is not a workable option, but no meaningful alternative to it is vouchsafed a serious hearing. Action is compromised, ideals are tainted, and efforts at social amelioration are tragi-comic illusions.

Forster's Howards End offers a less scathing treatment of imperialism, though it is also troubled by its implications. Jameson sees Forster as 'at best a closet modernist', but he uses Howards End as a litmus test for his theory that the reality of imperialism could be neither known nor acknowledged in the metropolitan centre that directed its operations but nonetheless manifested itself in modernist form. ${ }^{103}$ This theory leads him to ignore the novel's obvious thematic engagement with imperialism, especially through its representation of the Wilcoxes, whose wealth comes from trade in West Africa, who have a son making his way in Nigeria, and who are mockingly described as supermen of the future. Howards End is structured around the opposition between two families - the liberal, free-thinking Schlegels and the conservative, conventional Wilcoxes - and Forster is usually taken to sympathise with the former. But such conclusions are precarious in a slippery text that admits of no stable perspective; the novel's narrator is a protean figure whose apparently liberal sentiments are quite possibly as ironic as his sardonic treatment of Schlegels and Wilcoxes alike.

The Wilcoxes' view of life is initially treated with horror by the more emotional and idealistic of the Schlegel sisters, but as the novel unfolds and the second sister (Margaret) becomes close to Wilcox père, this view is given a second hearing. Margaret comes to think that the Wilcoxes' social beliefs are 'a real force' and that the virtues they 
uphold 'have formed our civilization' ( $H E$ 88). But this civilisation is not formed by such virtues alone. The novel makes it clear that the economic basis upon which it rests relies on a global capitalism that makes profits out of the British Empire. The Wilcoxes do not resemble English industrialists like the Criches in Lawrence's Women in Love (1920) or commercial entrepreneurs like the Ponderevos in Wells's Tono-Bungay (1909). They are businessmen whose wealth is generated by imperial trade. Pace Jameson, the novel's focus on imperialism turns out to be central to its treatment of the Schlegel/Wilcox opposition, and its interest in imperialism's wider ramifications is signalled from the very beginning of the narrative. Its initial account of the Schlegel sisters' family origins emphasises their father's contempt for PanGermanism and British imperialism because he sees them as equally commercial and materialistic, a diagnosis that is later borne out by the nationalist rivalry between the anglicised Schlegels and their German cousins.

Unlike her father, Margaret is more inclined to gloss over the parallels between two similar forms of imperial expansionism in order to emphasise their social benefits. In doing so, she draws on the familiar discourse of the civilising mission and the white man's burden. If Wilcoxes and their kind 'hadn't worked and died in England for thousands of years', then Schlegels 'couldn't sit here without having [their] throats cut', since either 'savagery' would reign or life wouldn't have 'moved out of protoplasm' (HE 149), a perspective that echoes Marlow's conviction that the Congo is a primordial and ahistorical zone - 'a prehistoric earth' (HD 138). Although she professes to be bored by the idea of the Empire, the older Schlegel appreciates 'the heroism that builds it up' (HE 95). This 'heroism' is a murky affair in Howards End, however. It upholds the sanguine Wilcoxian view of it about as much as Heart of Darkness endorses Marlow's aunt's conviction that Europeans are in Africa to wean "'ignorant millions from their horrid ways"' (HD 113). The following passage, in which Margaret goes to the offices of Wilcox's Imperial and West African Rubber Company, is instructive:

She was glad to go there, for Henry had implied his business rather than described it, and the formlessness and vagueness that one associates with Africa itself had hitherto brooded over the main sources of his wealth. Not that a visit to the office cleared things up $[\ldots]$ even when 
she penetrated to the inner depths she found only the ordinary table and Turkey carpet, and though the map over the fireplace did depict a helping of West Africa it was a very ordinary map. Another map hung opposite, on which the whole continent appeared, looking like a whale marked out for blubber [...] She might have been at the Porphyrion or Dempster's Bank, or her own wine-merchant's. Everything seems just alike in these days. But perhaps she was seeing the Imperial side of the company rather than its West African, and Imperialism always had been one of her difficulties. (HE 167)

It is hard to read this passage without noting further parallels with Heart of Darkness, which begins with 'a mournful gloom, brooding motionless over the biggest, and the greatest, town on earth' (HD 103 ) and in which the despoliation of Africa could be compared with the image of a country being dissected as though it were nothing more than an inert carcase. Margaret's penetration of the office enacts in miniature Marlow's journey up the Congo, and like him she remains unenlightened. The opaque nature of Wilcox's business is attributed to the African continent just as Kurtz's insanity is explained in part by reference to the wilderness that has marooned him. The phrase ' $a$ helping of Africa' underscores the ambiguous nature of Wilcox's business, since it plays on two possible meanings: aid to Africa and a portion taken away from Africa and then consumed.

No less revealing is the familiarity of the office, its resemblance to the institutions with which Margaret is in daily contact in London, for this suggests that the Imperial and West African Rubber Company appears to be a business like any domestic one and thus initially seems to be unremarkable. But the maps in the office indicate that this particular business is in fact inseparable from a global economic network that exploits overseas markets. As in Heart of Darkness, the operations it engages in take place far away. All that is visible in London is the official 'Imperial' aspect of the business, while the 'African' side is hidden from view. The point here is that Howards End registers this tension thematically, thereby inviting its readers to think further about the possible discrepancy between official and unofficial accounts of the business of empire; it is misleading to argue (as Jameson does) that imperialism cannot be the conscious subject of such texts, although it is certainly true that Howards End addresses the imperialist problematic in an oblique fashion, in keeping with its more general 
narratorial instability. The novel's narrator suggests at one point that while it is tempting to think of the 'Imperial' type as 'a super-yeoman, who carries his country's virtue overseas', he is in reality 'a destroyer' (HE 276). By the end of the text, the fear that life is being 'melted down, all over the world' (HE 290), once again reminds us of the globalising economic forces to which the novel has persistently drawn attention by making it clear that the nation's wealth depends on profits made under dubious circumstances in the empire's murky outposts of 'progress'.

If the Wilcoxes see capitalism and imperialism as impersonal forces that make for the general good, then the politician Dalloway in Woolf's The Voyage Out (1915) is even more of an idealist, believing as he does in '[u]nity of aim, of dominion, of progress' and the 'dispersion of the best ideas over the greatest area' ( VO 55). Although he acknowledges that there are 'drawbacks' to this vision, since he is aware that there are 'horrors - unmentionable things done in our very midst!', Dalloway nonetheless maintains that 'the English seem, on the whole, whiter than most men, their records cleaner' (VO 56). This is the view Marlow offers in Heart of Darkness when he praises the areas of Africa that are controlled by the British. And like Marlow, Dalloway holds to a traditional view of gender. Despite his awareness of imperialism's seamy side, he is able to preserve his ideals and stay active in public life because his wife - safely ensconced in the domestic sphere - is denied the knowledge that would undermine commonly held assumptions about progress and civilisation. He has kept to his ideals, he explains, because he has 'been able to come home to [his] wife in the evening and to find that she has spent her day in calling, music, play with the children, domestic duties - what you will; her illusions have not been destroyed' (VO 56).

In The Voyage Out, England's imperial destiny is presented in near parodic terms. When Dalloway's wife reflects on 'what it really means to be English', she immediately thinks of imperialism, which she sees as a manly civilising project: 'One thinks of all we've done, and our navies, and the people in India and Africa, and how we've gone on century after century, sending out boys from little country villages and of men like you, Dick, and it makes one feel as if one couldn't bear not to be English!' (VO 42). Dalloway, in turn, sees imperialism in terms of historical, political, and legal continuity. It is an organic process that he associates with 'conservative policy', which 'gradually enclosed, as though it were a lasso that opened and caught things, 
enormous chunks of the habitable globe' ( $V O$ 43). The Voyage Out systematically undermines this self-serving expansionist rhetoric. Dispensing his platitudes, Dalloway is 'a battered martyr, parting every day with some of the finest gold, in the service of mankind' ( VO 56), an image that reverses the truth of imperial exchange captured in Heart of Darkness when Marlow refers to a 'stream of manufactured goods, rubbishy cottons, beads, and brass-wire sent into the depths of darkness', in return for which comes 'a precious trickle of ivory' (HD 119). The Voyage Out offers a subtle critique of imperialism. It shows both that the English economy depends on foreign trade and that overseas trade is based on a hierarchical relationship between the colonisers and the colonised, which conceals two kinds of exploitation: economic and visual.

These two forms of exploitation are most clearly in play when a group of English tourists takes a trip to an up-country village. One character has already observed that the handkerchiefs made by the natives are a source of easy money: 'They don't know what they're worth, so we get 'em cheap. And we shall sell 'em to smart women in London' (VO 222). Her husband, in turn, is convinced that 'wonderful treasures lay hid in the depths of the land' and that what the English party has thus far seen are 'merely trifles picked up in the course of one short journey' (VO 224). Hand-crafted items are seen here as exotic products that, because they are so attractive to the eye, can easily be marketed to a metropolitan clientele avid for foreign knick-knacks. But the colonial gaze extends beyond such objects in The Voyage Out, it seeks to embrace the natives themselves, treating them as curios that can be observed with impunity. The up-country trip is given a political edge when some of the characters imagine that they are 'great captains sent to colonise the world' ( $V O$ 250). The act of looking (now conceived as an aggressive act that depends on a racialised hierarchy of power) is connected to a wider history of violent conquest, and the exploitation of natives who make handkerchiefs is related to a broader set of imperial practices and to the forms of resistance they generate. When the Europeans reach the village, they are subjected to a reverse gaze, which not only challenges their presence but also positions them as a military force: 'As they sauntered about, the stare followed them, passing over their legs, their bodies, their heads, curiously, not without hostility, like the crawl of a winter fly [...] When sweetmeats were offered them, they put out great red hands to take them, and felt themselves treading cumbrously like tight-coated soldiers among these soft instinctive people' ( VO 269). ${ }^{104}$ 
In other works from the period, the treatment of imperialism is inseparable from the question of how it is to be broached. Stephen Hero (1901-1906), the ur-text of Joyce's A Portrait of the Artist as a Young Man (1916), is interesting in this respect. A draft work that was never published in Joyce's lifetime, Stephen Hero is preoccupied with the presence of the British in Ireland but engages with this issue by seeing it as a conundrum that the writer must evade. The obliquity of approach discernible in texts like Heart of Darkness, Howards End, and The Voyage Out can be understood both as a response to the difficulty of engaging or coming to terms with imperialism and as a sign of their ambivalence about it. In Stephen Hero, the would-be writer within the narrative chooses a strategy of evasion in order to resist the pressure being put on him to address it. Here we see a nascent modernism that figures the writer as an apolitical free-thinker whose primary concern is to make himself into an artist whose chief commitment is to his or her art. This figure's isolation takes place in a specific historical context; his refusal to speak on behalf of various contending groups has a clear political valence. And this refusal is the cause of anxiety, as can be seen from a scene in which the novel's protagonist ducks the linked issues of Irish nationalism and the Irish language:

- And don't you think that every Irishman worthy of the name should be able to speak his native tongue?

- I really don't know.

- And don't you think that we as a race have a right to be free?

$\mathrm{O}$, don't ask me such questions, Madden. You can use these phrases of the platform but I can't.

- But surely you have some political opinions, man!

- I am going to think them out. I am an artist, don't you see? (SH 60)

By disowning knowledge of nationalism, mocking its rhetoric, pleading for time, and implying that politics and art are different discourses, the neophyte writer both registers the pressures put on him to be politically engaged and resists them. This is hardly a resolved stance (neither here nor in Portrait) but is in process throughout the text and is continually beset by opposing demands that cannot be reconciled. When Stephen delivers his inflammatory lecture at the university, we are told that in seeking 'to define his own position for himself' ( $\mathrm{SH} \mathrm{81)} \mathrm{he} \mathrm{is} \mathrm{forced} \mathrm{to} \mathrm{define} \mathrm{his} \mathrm{view} \mathrm{of} \mathrm{the} \mathrm{artist's} \mathrm{function} \mathrm{against}$ 
the nationalist politics in which he cannot bring himself to believe. This is in part because he sees Irish nationalism as a form of juvenile play-acting and in part because his belief in the primacy of the aesthetic forbids him from subordinating his work to any religious or political ideologies: 'The programme of the patriots filled him with very reasonable doubts; its articles could obtain no intellectual assent from him. He knew, moreover, that concordance with it would mean for him a submission of everything else in its interest and that he would thus be obliged to corrupt the springs of speculation at their very source' ( $S H$ 81).

It is the 'springs of speculation' that are to be preserved at all costs here, the assumption being that any art denied the right to evolve freely will be compromised. This defence of art's autonomy pits the writer against those who expect Irishmen to participate in the nationalist cause, either by defending Irish culture and promoting its language or by engaging in violent revolution. It is revealing that those who oppose Stephen's thesis discern something 'revolutionary' in it, and it is striking how frequently the word revolutionary crops up in the novel, for the conception of the aesthetic that he articulates certainly challenges the idea that the Irish writer should serve his country by taking political sides. Stephen knows that in this context his theory is indeed dangerous. Tellingly, he describes it as 'the first of [his] explosives' ( $\mathrm{SH} \mathrm{86)}$, and he takes 'every precaution to ensure in it a maximum of explosive force' ( $S H$ 53). Bombing was part of the Fenian physical force movement at this time, so these are carefully deliberated words. The refusal to engage in nationalist politics is presented as a devastating political act - a statement of radical noncompliance with the nationalist analysis and its strategies. The alternative offered by the autonomous artist is complete freedom of thought on the grounds that those who listen to him 'might need only the word to enkindle them towards liberty or that, at least, his trumpet-call might bring to his side a certain minority of the elect' ( $S H$ 53-54). It is liberty of mind that is at stake here, not political liberty, the 'word' of the independent artist superseding both the debased Word of God and the dubious rhetoric of politicians.

To what extent, then, is the artist depicted as an aesthete here? In Stephen Hero, the text's protagonist presents himself as the only figure who has the power to crystallise what is most essential in reality and then reshape it, and this elevated vision of the writer's capacity and role implies that he is not an ivory tower recluse. The 'supreme artist', 
Stephen informs us, can 'disentangle the subtle soul of the image from its mesh of defining circumstances most exactly and re-embody it in artistic circumstances chosen as the most exact for it in its new office' ( $\mathrm{SH}$ 82). As in Baudelaire's and Conrad's conceptions, the artist is imagined here as a far-seeing visionary who comprehends not the external aspects of life but its deep 'unalterable laws' ( $S H$ 83). The writer 'is the intense centre of the life of his age to which he stands in a relation than which none can be more vital. He alone is capable of absorbing in himself the life that surrounds him and of flinging it abroad again amid planetary music' ( $\mathrm{SH} 85$ ).

The Romantic origins of this heroic view of the artist and the power of the aesthetic are clearly visible here, though Joyce's use of free indirect discourse in Stephen Hero should give us pause, for it suggests that its protagonist's views to some extent are being ironised (as they will be even more mercilessly in the later Portrait). And the desire to speak for one's age or country certainly is shown to be problematic in Stephen Hero by its protagonist's aestheticist convictions and his egoist philosophy of life. He admits, for example, 'that he could not take to heart the distress of a nation, the soul of which was antipathetic to his own, so bitterly as the indignity of a bad line of verse' ( $S H 151$ ), and he discloses his radical individualism when he asserts that 'he felt the need to express himself such an urgent need, such a real need, that he was determined no conventions of a society, however plausibly mingling pity with its tyranny, should be allowed to stand in his way' (SH 151).

The influence of egoist thought on Joyce can be discerned here. ${ }^{105}$ No less important is the wide understanding of what constitutes tyranny. For the novel's scepticism about Irish nationalism is more than matched by its hostility to Catholicism. For Stephen, the 'Roman, not the Sassenach', is 'the tyrant of the islanders' ( $S H$ 57). But what connects Irish nationalism and Irish Catholicism is a shared language and, as in Portrait, it is from the tyranny of this language (with all its unspoken cultural assumptions) that the writer seeks to free himself. Stephen Hero, in other words, is already grappling with the problems that Joyce would explore in more detail in later texts, above all the difficulty of challenging or escaping from culturally dominant discourses and ways of thinking when one is forced to use the language(s) in which those very discourses and modes of thought are grounded. The self-creation of the artist turns out to be inseparable from his exploration and criticism of the codes to which he is heir and by which - as Portrait makes clear - he feels he has been colonised. Hence the self-conscious mockery in Stephen Hero of its 
protagonist's faith in a 'freedom which would dress the world anew in vestments and usages begotten of enslavement' ( $S H$ 167).

But if the efficacy of the novel's aestheticist and individualist language and ideas are called into question, then so too is the receptiveness of its intended readership - the Irish people. Just as Heart of Darkness worries about the capacity of its audience to grasp its obscure message, so Stephen Hero agonises over the Irish writer's relationship to an uncomprehending and hostile public. It seems unlikely, the novel implies, that a slew of its protagonist's compatriots will show much interest in his arcane speculations and fantastical aspirations. The tension at the centre of the novel is that the aesthetic theory it outlines sits so uneasily and uncomfortably with the reality it seeks to engage. Everyday Dublin life is depicted as parochial, hypocritical, and paralysed. The impasse reached in Stephen Hero is a double one: the artist is at odds with his society, and the aesthetic he upholds exposes the impassable gulf between himself and those he seeks to address. It is hardly surprising that in Portrait the aspiring artist will declare that silence, exile, and cunning are the only strategies available to him in the face of an obtuse and cowed society. This much could have been predicted from the outraged reactions to his forerunner's lecture in Stephen Hero: 'The moral welfare of the Irish people was menaced by such theories. They wanted no foreign filth' ( $\mathrm{SH} \mathrm{107).}$

\section{Early Modernist Drama}

Anxiety about filth, whether foreign or not, featured prominently in reactions to a good deal of modern drama in the 1890s and 1900s. Several plays from the period suffered at the hands either of the censors or, if they were staged, of an outraged public that frequently could not stomach the bitter fare being doled out to them. The importance of drama to modernism has often not been recognised. Some critics have suggested that this neglect is explicable in terms of modernism's scepticism about theatre in general. Christopher Innes suggests that 'theatre's intrinsic connection to physical reality and social existence' renders certain 'key modernist principles inapplicable'. He has in mind modernism's desire to 'assert itself as an autonomous activity, independent of external experience', and its interest in 'pure form', which conflict with drama's basic mimeticism. ${ }^{106}$ But the tenets to which Innes refers are at best partial features of modernism's variable and 
often internally conflicted practices; the writers who are most closely associated with its innovations never saw literature as an asocial and purely aesthetic form, though they certainly resisted the idea that it should serve a didactic purpose or exert an immediate social influence (as, to take a counter example, Wells believed it should). ${ }^{107}$ In most cases, they saw the radicalisation of art as a means of renewing or revolutionising modern culture and society. That said, it is true that drama tends to be ignored in histories of modernism, and this is possibly because a key trajectory in the development of modern theatre (though it was by no means the only one) was realist in orientation. If modernism is conceived primarily as a challenge to an outdated realism (as in Woolf's polemics against Bennett, Galsworthy, and Wells, say), then modern theatre's interest in realism can be seen as retrogressive rather than innovative, and the drama it was involved in producing can be written out of literary history. ${ }^{108}$

This is a curious line for critics to take, however, because modernism not only discloses a wide range of forms but also often manifests a desire for a greater realism. Regarding such writers as Henrik Ibsen (in drama) and Gustave Flaubert (in fiction) as their major progenitors, various modernists sought to radicalise nineteenth-century conventions rather than to jettison them in their entirety. Innovation in such cases took place partly because writers wanted to assert the autonomy of art - its freedom from moralistic views of literature's purposes - and partly because they considered that earlier realist modes failed to represent human life adequately. The aim was to improve on these earlier modes by deepening their realism. When Virginia Woolf urged her readers to 'look within', she followed up this injunction with an appeal to their apprehension of reality, asking if 'life' was really “"like this"'? (WSE 9). The German dramatist Bertolt Brecht rejected the assumption that nineteenth-century realist canons should be set in stone: 'Methods become exhausted; stimuli no longer work. New problems appear and demand new methods. Reality changes; in order to represent it, modes of representation must also change'. ${ }^{109}$

A significant number of modernists sought to transform nineteenthcentury realist conventions in the hope of making them more relevant to contemporary concerns, and many of the writers dealt with in this book thought of their work as part of a wider realist project. Joyce's early work is a case in point, his indebtedness to Ibsen disclosing his early commitment to a new form of truth-telling. Pound expressed his hostility to the theatre - 'a gross, coarse form of art' - in a tetchy letter 
to Joyce in which he was critical of the latter's play Exiles. But he added that if 'there were an Ibsen theatre in full blast' ( $P / J 46)$, then Joyce's play could be staged, although in a climate characterised by 'the Granville Braker [sic] tone' $(P / J 47)$ this was both impossible and undesirable. Pound developed this argument in a later essay. He argued that Ibsen's power as a dramatist had been diluted by an English stage dominated by Barker and Shaw and that this dominance made Joyce's work unperformable. For Pound, Ibsen 'was a true agonist, struggling with very real problems', and it was Ibsen who, more than anybody else, had "made us "our world," that is to say, "our modernity"; Shaw's work, in contrast, was 'Ibsen with the sombre reality taken out' (P/J 5l) because Shaw was 'not a man at prise with reality', and 'being at grips with reality', Pound insisted, was 'the core of great art' (P/J 52).

Pound, then, saw Barker and Shaw as purveyors of a safely diluted Ibsenism. He was unwilling to accept that their work had brought anything significantly new to the stage. But this uncompromising view (the counterpart to his animus against Arnold Bennett in the sphere of fiction) was unfair not only to Barker and Shaw but also to the new realism with which they were associated, alongside such writers as John Galsworthy, St John Hankin, D. H. Lawrence, John Masefield, and Elizabeth Robins. These writers' work was unimaginable without the prior example of Ibsen, and although their plays were less challenging than the latter's best drama, they nonetheless disrupted the conventions of the 'well-made' play, dealt openly with social problems, and urged audiences to engage with troubling issues. Ibsenism was typically associated with 'a belief in a socialist political philosophy; a resistance to unthinking adherence to social convention; and, closely allied with that, a belief in a new role for women in society'. ${ }^{110}$ The dramatists who followed in the Norwegian's footsteps were preoccupied with the same issues, and they brought a much needed honesty and seriousness to the English stage, though it should be noted that the class focus of their plays differed considerably, especially in Galsworthy's and Lawrence's writing and also in the work of the Lancashire playwrights who were associated with Manchester's Gaiety theatre (principally Harold Brighouse, Stanley Houghton, and Allan Monkhouse) and who took a broadly bourgeois form of naturalist realism and transformed it into a working-class model.

Shaw was especially important in popularising Ibsen, as was the influential drama critic William Archer. Thomas Postlewait has argued that his Ibsen campaign 'served to fuel the whole theatre movement for 
change, so that by the beginning of the twentieth century the London stage had indeed entered the modern era'. ${ }^{11}$ Shaw was an equally vocal defender of Ibsen's work, and his own plays were at the heart of the new drama that emerged in England in the 1890s and early 1900s. In The Quintessence of Ibsenism (1891), he argued that the post-Ibsenite play was characterised firstly by a blending of discussion and development, and secondly by the use of techniques that made the audience part of the drama they were witnessing. As for Ibsen's so-called immorality, this was simply a necessary challenge to conventional values that were too meekly accepted; the 'vigilant openmindedness of Ibsen [...] must at once greatly deepen the sense of moral responsibility'. ${ }^{112}$ For Shaw, Ibsen's questioning spirit, his refusal to suggest solutions to the difficult issues his plays explored, and his willingness to challenge established verities showed him to be a modern writer par excellence. So prevalent was Ibsen's influence that when the director Tyrone Guthrie looked back on this moment from the perspective of the 1930s, he remarked that 'Ibsenish ideas, as well as an ever-increasing realism, are apparent in Galsworthy, in Granville Barker, and in the Manchester School'. ${ }^{113}$

Playwrights like Barker, Galsworthy, Hankin, Masefield, Robins, and Shaw saw themselves as no less modern. In their dramas, they addressed such issues as the changing nature of sexual mores, marital life, women's suffrage, double standards in public and private life, generational and class conflict, the position of women in society, abortion, labour relations, the criminal justice system, and penal reform. Drama for these playwrights was a medium that could contribute to the rectification of social ills if it were permitted to deal with the urgent questions of the day. But they also tried to break free from what they saw as the stultified conventions of the 'well-made' play. Barker, Galsworthy, Hankin, and Lawrence all drew on Symbolism in some of their works in an attempt to give a deeper significance to their naturalist representations, while Robins's elaborate staging in Votes for Women of a public suffragette meeting directly involved the audience in the events of the play, making them part of the spectacle they were ostensibly observing from a removed position. ${ }^{114}$ Robins was working in something close to an agitprop manner here, choosing a theatrical strategy that made perfect sense in the context of the suffragette movement. ${ }^{115}$

The plays written by these dramatists required theatres willing to produce them. The most important of these were the Court Theatre under the management of Barker and J. E. Vedrenne between 1904 
and 1907 and the 1910 repertory season at the Duke of York's Theatre. Barker saw the Court Theatre as a continuation of the work done in the 1890s by J. T. Grein's Independent Theatre Society, the New Century Theatre, and the Stage Society. The Independent Theatre was significant because of its Ibsen productions and because it 'imported the notion of alternative theatre into Britain and gave some writers, notably Shaw and Elizabeth Robins, an opportunity to experiment before an audience', while the Stage Society, which succeeded the Independent Theatre, put on private performances of plays that struggled to get past the censor. ${ }^{116}$ Censorship was a major issue in the period before the First World War. Several plays were prevented from being staged publicly, among them Barker's Waste, Laurence Housman's Pains and Penalties, Ibsen's Ghosts, Eden Phillpotts's The Secret Woman, Shaw's Mrs Warren's Profession, and Oscar Wilde's Salomé. There was an ongoing and unresolvable conflict here between conservative attitudes to 'public decorum' and the theatrical avant-garde's desire 'to expose and analyse' social problems. ${ }^{117}$

No less important to the development of modern drama in England was the Gaiety Theatre in Manchester, which was funded and managed by Annie Horniman. Prior to establishing the Gaiety in 1907, Horniman had helped to set up the Abbey Theatre in Dublin (financing it out of her own pocket) and had enabled Florence Farr to put on a season at London's Avenue Theatre, which included the first West End production of a Shaw play: Arms and the Man (1894). Rex Pogson suggests that this influential staging of Shaw 'outside the private societies' can be said to mark 'the beginning of the modern theatre movement in this country'. ${ }^{118}$ Ibsen's drama was once again important here. Horniman had been in the audience for the first performance of Hedda Gabler in Munich in 1890, and she went on to champion Shaw's plays at the Gaiety. Horniman sought to create a catholic theatre that was wedded neither to any particular period of drama nor to any single aesthetic; the aim, rather, was to put on a range of old and new plays. Between the years 1907 and 1921, the Gaiety produced work by such figures as Brighouse, Basil Dean, Galsworthy, Houghton, Ibsen, Maurice Maeterlinck, Monkhouse, Shaw, Hermann Sudermann, and Emile Verhaeren. If the influential critic William Archer found some fault with the company's stagings and acting, he nonetheless observed that 'this Manchester movement is the most important fact in our theatrical history since the opening 
of the Vedrenne-Barker campaign at the Court Theatre', and Pogson rightly describes the Gaiety as 'the parent of the vast modern repertory movement'. ${ }^{119}$

Writers and critics who were inspired by European innovations in drama and who saw themselves as part of a nascent avant-garde demanded a bolder and more innovative theatre in England. Huntly Carter's The New Spirit in Drama and Art (1912) is a good example of the dissatisfactions expressed by modernistically inclined critics. A wide-ranging survey of European theatrical developments, The New Spirit in Drama discussed the work of playhouses in Bayreuth, Berlin, Budapest, Kraków, Dresden, Leipzig, Moscow, Munich, Nuremberg, Paris, St Petersburg, Vienna, and Warszawa. Carter's overriding aim was to show just how far English drama had been left behind by European theatre. He was interested in the creation of 'a truly national theatre' (a much discussed topic in the late Edwardian period), but he argued that this would only come about if the English stage were opened up to wider 'European influences'. ${ }^{120}$

Two aspects of Carter's thesis about what was needed are worthy of note: firstly, he was interested in a 'decorative' modernism, which was influenced by the performances and stage designs of the Ballets Russes and had affinities with the group around the little magazine Rhythm; secondly, this version of modernism was influenced by the Wagnerian idea of the Gesamtkunstwerk - the total work of art. As Carter put it: 'My own idea of the finest form of national drama which this country will see adopted comprises a rhythmic conception of play, player, decoration, and music. This drama will be represented in a rhythmic form of theatre. Everything henceforth is to be orchestrated to produce a single but infinitely varied total effect'. ${ }^{121}$ And Carter, like T. S. Eliot, T. E. Hulme, and Ezra Pound, understood modernism's invocation of the new as at least in part a rehabilitation of lost ideals and traditions; the present period, he argued, was 'an age of rediscovery', and what else was modernism 'but bringing old things up to date?' 122 Carter was interested in spiritual renovation above anything else. For him, Ibsen's significance lay in the 'new spiritual stimulus' that he had brought to the theatre. Thus those who saw Ibsen as a rationalist and a reformer misunderstood his true import, with damaging consequences for the development of drama, because this misreading had 'bred a race of realists where only symbolists ought to be' and had effectively 'destroyed the theatre'. ${ }^{123}$ Carter, in short, was urging a different view of theatre's possibilities 
and the direction it should take from the tough-minded realism associated with Barker, Galsworthy, Hankin, Robins, and Shaw.

The person most obviously associated with a non-realist view of what the modern theatre could achieve was the visionary director Edward Gordon Craig. Above all others, it was Craig who sought to revolutionise the English stage, and it was his productions of Dido and Aeneas and The Masque of Love in 1900 at the Hampstead Conservatoire, Ibsen's The Vikings in 1903 at the Imperial Theatre, and later on Hamlet (co-produced with Stanislavsky) in Moscow in 1912 that gained him both notoriety and respect among modernist writers and artists. Reviewing The Vikings, James Huneker focused on Craig's tableau-like approach to staging and action: 'From above falls a curious, sinister light which gives purplish tones to the stony surfaces and masks the faces of the players with mysterious shadows. The entire atmosphere is one of awe, of dread'. ${ }^{124}$ Craig was committed to a Symbolist artistry that made no compromise with naturalism, although he was unable to put most of his abundant and ambitious ideas into practice. Symbolism, he maintained, was 'the very essence of the Theatre' and was the root of all life and all true art. ${ }^{125}$

Many of Craig's ideas were communicated through his magazine, The Mask, which he saw as a weapon against realist drama and commercial theatre. The Mask attacked the market-driven theatrical traditions that Craig detested and advanced his vision of a total art of drama to be based on rhythmic movement and directed by a single controlling intelligence - that of the all-powerful director. The Mask looked for a return to forgotten theatrical techniques, just as Eliot and Pound aimed to resuscitate certain poetic traditions, but like these modernist poets, Craig was selective in what he took from the past. He was consciously forging an alternative theatrical genealogy in order to devise a new drama out of elements that he adapted from abandoned conventions. In 'The Art of the Theatre', he called for a total theatre characterised by seamless flow and the integration of all its different parts, although he conceived this theatrical vision not as a Wagnerian Gesamtkunstwerk but as a simplified drama that disposed of all extra-theatrical elements. ${ }^{126}$ For Craig, as for other modernists, the path to renewal lay in a return, as Eliot later put it, to 'forgotten standards' (UP 71). 'I believe', Craig wrote, 'that the very material of the theatre needs simplifying [...] I do not wish to revert to an old manner, but I do not want to depart from a noble tradition. I wish to rebuild on old truths'. ${ }^{127}$ 
Huntly Carter made the same point in The New Spirit in Drama (1912) when he argued that a 'message of simplicity' lay at the heart of 'the three forces that have come to us from Berlin, St Petersburg, and Moscow' ${ }^{128}$ Craig returned to certain dramatic approaches not in the guise of the antiquary but in the spirit of a creator who sought to make past traditions relevant to modern theatre. He was, he wrote, less of a reformer than 'one who would put things in order'. ${ }^{129}$ Suspicious of the literariness of contemporary theatre, he wanted to create a visionary symbolic drama that expressed emotion through movement, gesture, and scene. His goal was 'a new kind of kinetic theatre - a synthesis of form, light, scene, figures and sound'. ${ }^{130}$ Grasping that he was never likely to be in a position to realise his vision of drama, Craig used The Mask to proselytise on behalf of his revolutionary ideas. ${ }^{131}$ The magazine became an unfolding manifesto, which lambasted most early twentieth-century drama and called for a visionary, as yet uncreated, theatre of the future. Using around seventy pseudonyms, Craig peopled The Mask with multiple voices - all of which represented himself in different guises - and then staged debates between them, always ensuring that the viewpoint he himself espoused won out. After The Mask folded, Craig started another magazine - The Marionette which included several of his puppet plays, but this new venture in 'little magazine' publishing lasted only till 1919.

Craig's passion for masks and marionettes derived from his interest in Greek drama and in Japanese Noh plays. He found in these traditions the reduction in actors' facial expressiveness that he desired. Masks enabled a few key emotions to be expressed, while the figure of the marionette dispelled the illusion of the real. Combined with stylised movement and Expressionist staging, masks and marionettes enabled the playwright to move from the particular to the universal. Ashley Dukes, who later worked with the Group Theatre of the 1930s, understood what Craig was after. Differentiating between 'the actor's make-up and the actor's mask', Dukes explained that the former sought 'an effect of naturalness', whereas the latter was artificial, aimed at 'dramatic creation', and disclosed the 'spiritual gesture' rather than the naturalistic act. ${ }^{132}$

Craig's hostility to realism can be seen in his Rearrangements (1915), the text in which he emphasised an inorganic (stylised, abstract) conception of drama over an organic (realistic, familiar) one and argued that actors should favour an 'unnatural mode of delivery', that scenery should be 'a non-natural invention, timeless, and of no locality', that 
stage lighting should be 'non-natural', and that performers should depend not on their individual skill but on the depersonalised qualities of the gesture and the mask. ${ }^{133}$ These arguments developed the position he had been outlining for several years. Performers, he maintained, 'must create for themselves a new form of acting, consisting for the main part of symbolical gesture'. Whereas in contemporary realistic drama 'they impersonate and interpret; tomorrow they must represent and interpret; and the third day they must create'. ${ }^{134}$ Acting should concern itself not with surface phenomena in an attempt to make everyday life believable but should look beyond it to a deeper reality.

Craig's boldest claim was that the actor should be replaced by what he called the Über-marionette. The concept of the Über-marionette drew on the traditions of puppetry, especially those of Java and Japan, but Craig did not have mechanical, wire-pulled dolls in mind so much as depersonalised, hieratic figures whose meaning was ritualistic and spiritual. Perennial truths and emblematic visions were to be communicated by means of symbolic movement and abstracted forms, just as Mondrian's painting sought to evoke universal harmonies and Kandinsky's art aimed to awaken the viewer's 'capacity for experiencing the spiritual in material and in abstract phenomena'. ${ }^{135}$ Craig argued in A Living Theatre (1913) that realism gave 'a grotesque and inaccurate representation of the outward and visible life, with the divine essence the spirit - the beauty of life left out'. ${ }^{136}$

In retrospect, 1911 can be seen as an important year for modernist drama in England. Craig published On the Art of the Theatre - in which he proclaimed that the actor should be replaced by the Über-Marionette and called for a non-literary drama built on 'ACTION, SCENE, and VOICE'; Max Reinhardt's company had a run at the London Coliseum; the Stage Society put on Anton Chekhov's The Cherry Orchard; and the Ballets Russes (under Serge Diaghilev) came to Covent Garden. ${ }^{137}$ But the most popular plays in the years before the First World War continued to be those that represented the new realism rather than the Expressionist ideas of Craig. Granville-Barker's Waste, for example, had such a successful run that tickets were hard to come by. ${ }^{138}$ Looking back on a life spent in the theatre, Ashley Dukes described Barker's directorial style as 'sensitive, shrewd, faithful', but he contrasted Barker's realist plays with the experiments that were then taking place in Europe and suggested that the drama being performed in England in the first decade of the twentieth century was largely unaware of them. ${ }^{139}$ Dukes acknowledged that Maurice Maeterlinck was 
beginning to be known, as was Gabriele D'Annunzio, but he argued that the most advanced drama was still associated with the post-Ibsenite 'drama of ideas' and not with the radical innovations in stagecraft called for by Craig or introduced in Europe by such figures as Reinhardt and Stanislavsky. Dukes made a telling observation when he wrote that 'Gordon Craig's productions and especially his writings were much discussed, but Granville Barker remained the only practising director of distinction'. ${ }^{140}$

There is a good deal of evidence to support this claim. Craig's ideas were praised by many who were sympathetic to modernism and who wanted to transform what they saw as an unimaginative theatre, but he was responsible only for a handful of productions after 1904. This was the year in which he left for Berlin to participate in an ill-fated production of Das Gerette Venedig (Venice Preserved), a decision that some interpreted as his conscious departure from a country that refused to invest in his innovative dreams. ${ }^{141}$ However, Craig's son claims that his father did not choose 'voluntary exile in Europe' but went to Berlin in the hope of earning money and of being given the opportunity to realise his ideas. In Index to the Story of My Days, Craig simply states that 'by 1904 I could stand no more the indifference [...] of everyone in England [...] and by the end of 1904 I was in Berlin'. ${ }^{142}$ Craig's revolutionary ideas were influential, but he was fated never to realise them in full; it is as a theorist of experimental drama that he is best known, not as a practitioner. The Art of the Theatre (1905), The Mask, and $O n$ the Art of the Theatre (1911) were widely read and eventually influenced such figures as Eugenio Barba, Peter Brook, Jacques Copeau, Jerzy Grotowski, and Robert Wilson, all of whom put into practice ideas that Craig had first articulated. ${ }^{143}$ In addition, The Actor and the Über-Marionette may well have heralded the 1920s experiments of Soviet theatre as well as 'the abstract experimental work of the Bauhaus, the methods of the German Expressionists, and Brecht's ideas about the actor's technique'. ${ }^{144}$

\section{Edward Gordon Craig and W. B. Yeats}

W. B. Yeats wrote in 'An Introduction for My Plays' that the Irish Literary Theatre had been a collaborative project. Established in 1898 by Augusta Gregory, Edward Martyn, and Yeats, it was based at the Abbey Theatre in Dublin, its aim being to put on productions of new 
drama by Irish playwrights, which it managed to do with great success. Jean Chothia suggests that the 'cultural and communal role the Abbey Company assumed in Dublin was such as most alternative and avantgarde theatres only dream of'. ${ }^{145}$ This drama not only dealt with Irish themes, legends, and traditions but also distanced itself from the realism of the new plays that were being produced in England. For himself, Yeats observed, he had desired a simplified stage that would enable the language of the dramatist to capture the audience's attention and, in pursuance of this aim, had sought 'vivid words' (EI 527) directed at ears 'attentive to every rhythm' (EI 528). Like Craig, Yeats sought a nonrealist drama, a poetic theatrical practice that would stir the imagination by addressing 'what is eternal in man' (EI 167) without getting lost among the irrelevant details of everyday life. He explained that the Irish Literary Theatre was established in the hope that people would be attracted by its challenge to commercial plays: it aimed to stage work that would be 'for the most part remote, spiritual, and ideal' (EI 166).

This anti-naturalism attracted Yeats to Craig's non-realist view of drama. As we have seen, there was a clear idealist strain in Craig's arguments, and this, as well as his use of Symbolist staging techniques, explains why Yeats was so drawn to his approach. In his essay 'The Theatre' (1899), Yeats maintained that the principal enemy of contemporary drama was commercial theatre, which in his view catered to the superficial desires of modern audiences and failed to engage with human beings' deepest needs; the theatre needed to be stripped down, made more symbolic and more elemental, in the hope that a new kind of audience might be created. Yeats's ambition for the theatre was that it would begin by attracting small groups of like-minded people but would in time become a popular and national theatre. He articulated his aim as follows:

We must make a theatre for ourselves and our friends, and for a few simple people who understand from sheer simplicity what we understand from scholarship and thought. We have planned the Irish Literary Theatre with this hospitable emotion, and that the right people may find out about us, we hope to act a play or two in the spring of every year; and that the right people may escape the stupefying memory of the theatre of commerce which clings even to them, our plays will be for the most part remote, spiritual, and ideal. (EI 166)

Simplicity, remoteness, spirituality - these were Yeats's watchwords. Drama was to distance itself from commercial theatre by refusing the 
lure of naturalism in order to release the imagination, which was 'the voice of what is eternal in man' (EI 167) and, as Blake had grasped, 'was the first emanation of divinity' (EI 112). Yeats sought a drama that could reach the bedrock of human existence, and this required a return to 'the simplicity of the first ages, with knowledge of good and evil added to it' (EI 167). The drama Yeats favoured was stylised, symbolical, and ritualistic. It called for decorative stage sets, a non-mimetic gestural acting style, and an incantatory mode of speech through which the art of poetry displaced the mundaneness of prose.

These ideas drew from numerous sources. Arthur Symons's writings were especially important. In several brief essays written at the turn of the century, Symons had not only lauded the new stagecraft associated with Maeterlinck and Craig but also praised the acting of Eleanora Duse, whose approach to performance he contrasted with that of the legendary Henry Irving. Written in 1902, Symons's 'A New Art of the Stage' was a suggestive piece, which argued that Craig's experimental theatre was boldly reinventing drama by creating 'an art no longer realistic, but conventional, no longer imitative, but symbolical' (SSA 224). Like Yeats, Symons was interested in this type of drama because it so determinedly turned its back on the naturalist traditions both writers contemned. He was struck by Craig's use of stage space, delighting in the artificial nature of his scenery and settings, which were laid out in geometric lines and demarcated squares. For Symons, Craig sought to take the audience 'beyond reality' ( $S S A$ 226) by means of an expressive form of drama. Craig's stagecraft was 'a protest against realism' (SSA 228) in the name of beauty and suggestiveness - precisely the aims Yeats had articulated in 'The Theatre'.

Symons's interest in Craig's use of geometric lines in his organisation of the stage and in his non-naturalistic scenery mirrored his fascination with Duse's approach to the art of acting. Duse was remarkable because her acting displayed a sculptural intensity: 'The outline of the face is motionless, set hard, clenched into immobility; but within that motionless outline every nerve seems awake, expression after expression sweeps over it, each complete for its instant, each distinct, each like the finished expression of the sculptor, rather than the uncertain forms of life, as they appear to us in passing' (SSA 220). This interest in a static, sculptural form of acting resonated with aesthetic ideas that would shortly become influential, as, for example, in Cubism and in Wilhelm Worringer's distinction between 'geometric' and 'empathetic' artistic styles, which would prove so important to T. E. Hulme and Wyndham 
Lewis. Symons's description of Duse's performance presents it as a series of discrete separate phases, like extended snapshots in a sloweddown diorama. What principally interested him about this kind of acting was that it made no attempt to be lifelike; on the contrary, by refusing a superficial imitativeness, it treated the body as the means by which 'the soul's visible identity' (SSA 221) could be disclosed. This view of acting as a necessary challenge to naturalism is remarkably similar to Worringer's account of art in Abstraction and Empathy (1908), for Worringer proceeds 'from the presupposition that the work of art, as an autonomous organism, stands beside nature on equal terms and, in its deepest and innermost essence, devoid of any connection with it, insofar as by nature is understood the visible surface of things'. ${ }^{146}$

The coincidence of Craig's ideas about staging and Yeats's interest in Symbolist drama has been amply documented. Yeats was entranced by Craig's Dido and Aeneas (1900) and his The Masque of Love (1901). He wrote to the director, telling Craig that his staging was 'distinctively original and artistic' and suggesting that it struck 'quite a new note in the Theatre'; a later letter was still more laudatory, informing Craig that he had 'created a new art'. ${ }^{147}$ Of Acis and Galatea (1902), Yeats remarked that in it Craig had returned to 'an art which has lain under the roots of the Pyramids for ten thousand years, so solemn it is'. ${ }^{148}$ Like Craig, Yeats was battling against naturalism and was trying to create a Symbolist theatre that transcended daily reality. Christopher Innes points out that when Craig provided the Irish National Theatre with a set of screens in 1909, Yeats 'experimented with them for almost a year' and 'completely rewrote Deirdre' in order to make the best possible use of their expressive possibilities. ${ }^{149}$ Yeats's The Hour-Glass, for which Craig also provided screens, appeared in The Mask, as did his essay 'The Tragic Theatre'. In a later note on The Hour-Glass, Yeats emphasised the importance of Craig's screens to the production and added that whenever the play was performed at the Abbey Theatre, the Fool wore 'a mask designed by Mr. Gordon Craig which makes him seem less a human being than a principle of the mind' ( $Y C W 684$ ).

In 1916, during the period in which he was collaborating with Pound, Yeats wrote a short play - At the Hawk's Well - which was performed in the drawing room of Lady Cunard's London house. Prior to the performance, he complained of the difficulties he was having with actors and musicians, for his aim was to create a Craigian kind of theatre, one 'in which masks are being used for the first time in serious drama in the modern world' ( $Y C W 871$ ). The main influence on At the 
Hawk's Well was Japanese Noh drama - redacted by Ernest Fenollosa and introduced to Yeats by Pound in 1913 - but Craig's ideas about the use of simple screens and Dulac's stylised designs were no less important. ${ }^{150}$ Yeats explained what motivated this experiment in drama in his essay 'Certain Noble Plays of Japan' (1916). Drawing on the traditions of the Noh, he had 'invented a form of drama, distinguished, indirect, and symbolic, and having no need of mob or Press to pay its way - an aristocratic form' (EI 221). The new form sought to move away from naturalism through a series of simplifications - of setting, scenery, acting, and declamation - in the belief that a more intimate connection with spectators would be established and that the inner truths of human existence would be communicated. No less significantly, this type of drama was intended for an elite audience, for those who did not belong to the hoi polloi and had no need for the cheap publicity generated by the fourth estate. For Yeats, a distancing, estranging dramatic technique enabled art to disclose the essential reality of human life, but this technique was principally to be of service to a few like-minded individuals.

The traditions of Noh drama and Craig's belief in the power of the mask came together in Yeats's explanation of why he turned to oriental conventions. In 'A Note on Masks' (1910), Craig argued that drama 'takes us beyond reality and yet asks a human face, the realest of things, to express all that'. ${ }^{151}$ Like Yeats, Craig had no patience with realism and naturalism, which he accused of mimicking the surface of human life and failing to reveal its deeper truths. This could be done with masks because, unlike the human face, which 'is over-full of fleeting expression', they make definite statements about human passions and convictions. ${ }^{152}$ The mask, Craig wrote, 'must return to the stage to restore expression - the visible expression of the mind - and must be a creation, not a copy'. ${ }^{153}$ Or, as the Expressionist writer Yvan Goll put it in 1918: 'We have forgotten entirely that the primary symbol of the theatre is the mask. The mask is rigid, unique, and impressive. It is unchangeable, inescapable; it is Fate'. ${ }^{154}$ Yeats's view of the mask differed subtly from Craig's conception of it. Although he also argued that its anti-vitalist intensity gave access to perennial truths, he was equally interested in the way that its stillness and rigidity focused attention on to the body of the actor or dancer whose stylised, rhythmic movements could express 'deep feeling' (EI 226). Referring to the anti-naturalism of Noh drama, Yeats suggested that its expressive power derived from its refusal of realism. Japanese dancers 'associate 
with every gesture or pose some definite thought', and their formalised movements give 'the impression not of undulation but of continuous straight lines' (EI 231).

A number of different ideas and influences are in play here. We have already noted that At the Hawk's Well drew on Craig, Dulac, and the Noh. We might also point out that Yeats's emphasis on straight lines recalls Symons's focus on the rectilinear nature of Craig's stage designs. Yeats would also have been aware of Vorticism through his connection with Pound, and visual Vorticism was associated above all with geometric forms. No less significant are the repeated references to 'rhythm', a concept in wide circulation just before the First World War, especially in the journals Rhythm and The Blue Review. But Yeats's thinking about drama went further back than these Edwardian and Georgian influences. His earlier response to Alfred Jarry's Ubu Roi in 1896 is no less important to our understanding of his later plays for dancers.

The explosive performance of Ubu Roi took place at Aurélie-Marie Lugné-Poë's experimental Théâtre de l'Oeuvre. Like Craig, Jarry was fascinated by the traditions of the commedia dell'arte and the grand guignol. At the age of fifteen, he staged an embryonic version of Ubu Roi with puppets. ${ }^{155}$ The 1896 play used real actors but had them perform in a marionette-like manner, so that, in Symons's words, they were 'living people pretending to be those wooden images of life which pretend to be living people' (SSA 238). A blackly comic, grotesque, foul-mouthed, and satiric rodomontade, Ubu Roi mocked absolutely everything. Symons saw it as an uncontrolled, indiscriminate critique, which ridiculed 'civilisation itself, sweeping all art, along with humanity, into the same inglorious slop-pail' ( SSA 236). But the play's spirit of negation needs to be seen in terms of Jarry's 'pataphysics', which he defined as 'the science of imaginary solutions' and which posited an alternative 'virtual' world. Pataphysics, Jarry explained, 'will explain the universe supplementary to this one; or, less ambitiously, will describe a universe which can be - and perhaps should be - envisaged in the place of the traditional one'. ${ }^{156}$ No such alternative is envisaged in the theatrical world of Ubu Roi, but it exists off-stage as an 'other' reality that is yet to be conceived and against which the 'merdre' (Jarry's scatological neologism) of the play asks to be judged.

Alastair Brotchie suggests that Jarry's use of the traditions of the puppet play was connected to his interest in primitivism, an interest he shared with the Nabis painters whose work he included in his 'little magazine' L'Ymagier. Jarry valued primitivism 'because it allowed 
for immediate and unmediated forms of expression' and because it disclosed 'a quest for universal meanings'. ${ }^{157}$ Behind the crazed grotesquerie of Ubu Roi may be discerned the desire for a return to prelapsarian innocence and purity. This desire was also the impetus behind Heinrich von Kleist's influential essay 'On the Marionette Theatre' (1810). Taking his point of departure from the fall of man as described in the book of Genesis, Kleist presented the marionette as the symbol of a preconscious and unified subjectivity, arguing that 'where grace is concerned, it is impossible for man to come anywhere near a puppet. Only a god can equal inanimate matter in this respect'. ${ }^{158}$ Craig's conception of the doll-like performer was close to this idea of Kleist's. 'The actor must go', he proclaimed, 'and in his place comes the inanimate figure - the Über-marionette we may call him'. This non-human interpreter was a kind of deity, a 'symbolic creature' that pointed beyond the thresholds of ordinary waking life and should be seen as the descendant 'of a great and noble family of images, images which were indeed made "in the likeness of God"'. ${ }^{159}$ For Yeats, in turn, especially in his Four Plays for Dancers, the marionette and the mask provided a way of expressing the kind of spiritual truth that a drama like Ubu Roi forbade. Present at the 1896 performance, he saw the play as a cultural watershed: 'After Stéphane Mallarmé, after Paul Verlaine, after Gustave Moreau, after Puvis de Chavannes, after our own verse, after all our subtle colour and nervous rhythm, after the faint mixed tints of Conder, what more is possible? After us the Savage God'. ${ }^{160}$

Yeats was also drawn to primitivism, but whereas Jarry's Ubu plays drew on its wild energies and left the pataphysical yearnings for an ideal world to be inferred from their revulsion with the present, Yeats's plays sought 'to invoke spiritual realities' (in R. F. Foster's words) and to forge the same kind of hieratic art he aspired to create through his poetry. ${ }^{161}$ Yeats wrote in 'The Return of Ulysses' that the more the poet purifies his mind, 'the more does the little ritual of his verse resemble the great ritual of Nature, and become mysterious and inscrutable. He becomes, as all the great mystics have believed, a vessel of the creative power of God' (EI 202). His use of Craig's screens in The HourGlass (1914), masks in At the Hawk's Well (1917), The Only Jealousy of Emer (1919), and Calvary (1920), and his reliance on marionette-style acting in all these plays aimed at a universalisation of theme and character. The stage in At the Hawk's Well is 'any bare space before a wall' ( YCW 297); the play's Guardian of the Well is dressed to resemble a 
hawk and, when she dances, is instructed to move like one ( $Y C W 304$ ); the patterned curtain in The Dreaming of the Bones 'must only symbolise or suggest' ( $Y C W 307)$.

Another aspect of Yeatsian drama makes clear how different its use of primitivist sources was from the iconoclasm of Jarry, which would go on to inspire Dada and the theatre of the absurd. ${ }^{162}$ Yeats pinned his faith to the declamatory power of the spoken voice, through which he sought to reassert the eternal truths of the poetic imagination. By simplifying scenery and hiding actors' faces behind masks, he aimed to still the stage so that 'words might keep all their vividness' ( $\Upsilon C W 23$ ) in keeping with his wider poetic project, which he described as 'clearing out of poetry every phrase written for the eye, and bringing all back to the syntax that is for ear alone' ( $\Upsilon C W 24$ ). Yeats's principal target was the chaos of contemporary urban life, although he also took a swipe at the deleterious influence of cinema - that modern technological medium par excellence. Accusing cinema of encouraging viewers to 'expect constant change' ( $Y C W 23$ ), he contrasted it with the calm grandeur of a Symbolist theatre. A slowed-down gestural acting style was to replace the ephemeral insights of modern psychology and the rapidly flickering images of film with the perennial truths of poetry. Jarry's madcap aesthetic offered one escape route from realism; Yeats's hieratic Symbolism offered a different one. It is thus revealing that for Yeats the first act of Synge's The Well of the Saints (1905) was able to captivate its audience 'though the two chief persons sat side by side under a stone cross from start to finish' ( $Y C W 23$ ). This emphasis on calm immobility is at odds with the Jarryesque tradition of schoolyard tomfoolery but pins its faith to a tradition of speech, gesture, and expression that culminates in Beckett's Happy Days (1961), a late modernist version of the 'stilling and slowing' that in Yeats's view of drama 'turns the imagination in upon itself' ( $\Upsilon \mathrm{CW} 24)$.

\section{The Modern Metropolis}

Yeats's interest in a Symbolist drama that sought a kind of willed stillness was inseparable from his hostility to a frenetic modern age. But other writers took their cue from the pace of daily life and sought to develop forms of writing that could engage with it. Modernism was an acutely urban phenomenon, and if it is wrong to think of it as only metropolitan, then its emergence and development are inconceivable 
outside of the cities in which most of its best-known practitioners lived, worked, and interacted. If Paris, London, and New York are the capitals most commonly invoked in accounts of where modernism happened, then these are only some of the places in which it was active in its many overlapping and mutually inter-animating practices and forms. It must be remembered as well that the major modernist cities were, almost by definition, in a constant state of flux, a fact that was welcomed by some as a sign of energising vitality and excoriated by others as a proof of debilitating chaos. F. T. Marinetti's 'The Founding and Manifesto of Futurism' (1909), a key document in the history of modernism, presents cities as the multiple sites of renewal because their embrace of new industries created vibrant, pulsing crowds that celebrated the fusion of humanity with technology. But Forster's Howards End, an anxious and defensive text, sees London as the source of a 'continual flux' that is associated with 'eternal formlessness' ( HE 156), which threatens to inaugurate a post-humanist world; the city is 'a tract of quivering gray, intelligent without purpose, $[\ldots]$ a heart that certainly beats, but with no pulsation of humanity' (HE 92).

Marinetti and Forster both emphasise the mobility of the cities they either exalt or denigrate. This mobility must be understood in two ways: movement within the city and movement between cities. Urban life in modernist writing is characterised by its kinetic energy, restlessness, and instability. People are always on the move, translating themselves from one place to another. This is as true of characters within novels as it is of the authors who wrote them, many of whom moved from country to country and from city to city (one thinks here above all of Conrad, Eliot, Ford, Joyce, Lawrence, Mansfield, Pound, and Richardson, but these names could easily be multiplied). If modernism was a metropolitan mode, then this is not only because its producers evoked the experience of inhabiting constantly changing cities but also because they lived and worked in them, forging networks, creating communities, and engaging in rivalries that depended on their living in close proximity to each other. ${ }^{163}$ The city was the site of complex interactions, unpredictable occurrences, spreading technologies (especially motorised vehicles, industrial machines, telephones, and underground trains), upward and downward social mobility, changing gender relations, population growth, and capitalist development. These new technologies were the subjects of excitement and trepidation. Their implications were perceived to be far-reaching but 
unclear. Nietzsche, for example, observed: 'The press, the machine, the railway, the telegraph are premises whose thousand-year conclusion no one has yet dared to draw'. ${ }^{164}$

Raymond Williams argues that the influx into the modern city of immigrants was the decisive factor in the development of modernism because these new arrivals found it a doubly estranging place. They experienced it as unfamiliar not only because it was modernising so quickly but also because it was culturally (and in some cases linguistically) foreign. It 'cannot too often be emphasized', he writes, 'how many of the major innovators were, in this precise sense, immigrants' for whom 'language was more evident as a medium - a medium that could be shaped and reshaped - than as a social custom'. ${ }^{165}$ Such shaping and reshaping took multiple forms, and although immigrants were important to the development of modernism in England, attention to their role should not obscure other factors, not least the roles played by class, gender, and race in the experience of urban life, where questions of access to the attractions offered by the metropolis loom large. The crowds that Marinetti exalted are a united group in his rousing manifesto, whereas in reality they would have comprised a wide range of individuals, each belonging to specific class fractions, some of whom might have found the city a place of drudgery and suffering rather than of release and joy. With reference to London, Peter Brooker reminds us that it was not only 'an advancing capitalist and imperial city' but also a 'geographically and socially differentiated' one. ${ }^{166}$

These two aspects of London feature prominently in early modernist writing about the capital. The need to 'read' the city, to draw attention to how variable a space it is, features in a number of texts written before the First World War, among them James's The Wings of the Dove (1902), Ford's The Soul of London (1905) and A Call (1910), Conrad's The Secret Agent (1907), Wells's Tono-Bungay (1909), Forster's Howards End (1910), and Woolf's The Voyage Out (1915). The accounts of the city offered by these texts differ, and their responses to urban experience and its consequences for human life disclose the heterogeneous nature of early modernism. Williams identifies five common modernist reactions to the city: as a place peopled by large numbers of strangers; as an isolating and alienating site; as a space that provokes anxieties about crime, especially because of the anonymity it offers miscreants; as a location that offers people the chance to forge new forms of solidarity; and as a source of exciting possibilities. 
The metropolis, then, provoked numerous fears and anxieties but also elicited welcome sensations and experiences. It was, as Williams puts it, 'an intense and visually and linguistically exciting process in its own right, from which remarkable new forms emerged'. ${ }^{167}$ These new forms both reacted to and engaged productively with urban phenomena. City life influenced the works that were produced within its ambience, but this does not mean that modernist literature somehow 'reflected' a prior reality. On the contrary, it took that reality as a thrilling and/or troubling nexus of developments that needed to be registered, explored, and reworked. Modernism intervened in city life by treating it as a pulsing vortex that affected its forms as well as its themes. As Scott McCracken puts it: 'Juxtaposed impressions, thoughts, images, and perspectives abound in modern art and literature; but, at the same time, there is almost always an attempt to understand urban experience through a formal aesthetic'. ${ }^{168}$

Ford's The Soul of London is a good early example of this combined attention to form, style, and subject matter. A classically impressionist text, it is a prismatic and Whistleresque book that deals with a multitude of topics, and Ford's paean to London is built out of fleeting glimpses from buses, cars, and trains: briefly captured moments flicker past. Ford's aim was to evoke the city's 'atmosphere' by throwing 'a personal image on to the paper' ( $S L 3)$. Describing 'clinging veils of steam' (SL 3), 'the blur of lamps in fogs' ( $S L 8)$, and 'mists, great shadows, great clouds' ( $S L 9$ ), Ford paints a Whistleresque London that is all shades, tints, and vapours. The cloud is a key image in The Soul of London, its wispiness suggesting that the essence of the metropolis will never be captured. It also hints at a blurring of boundaries that evokes the city's assimilationist spirit; what Ford wants to convey is 'the idea that all these human beings melt, as it were, into the tide of humanity as all these vapours melt into the overcast skies' ( $S L 3$ ). Ford's imagery aligns him with the pluralism of the social 'melting-pot', and London becomes the site of cultural diversity. This diversity is signalled by the text's insistence on the many perspectives from which London needs to be observed, its emphasis on the impossibility of an all-embracing view, its evocation of the capital's natural history, and its interest in contrasts. London, Ford claims, is 'illimitable' (SL 15).

Ford was also interested in drawing attention to the disconnected nature of urban experience in both The Soul of London and A Call. Considering the effect on people of reading daily newspapers, with their various topics jostling for space on a single page, he suggested that 
'[c]onnected thinking has become nearly impossible' (SL 88). Because modern cities were expanding so rapidly, they were bustling and crowded places, characterised on the one hand by a sense of positive energy and on the other hand by ever more impersonal contacts between people who scarcely knew each other. The modern metropolis can be seen as a schizophrenic space: the site of new freedoms, exciting events, technological advances, and changing relationships, but also of noise, dirt, disorder, alienation, and anxiety. Ford registers the impact of sensory overload in the city by suggesting that people could not always process events and thus had difficulty in making sense of the world around them. In $A$ Call, he went further, citing claims 'that the constant string of vehicles passing us in the streets of London so acted on the optic nerves that general paralysis was often induced' ( $A C 49$ ).

The Soul of London suggests that it is impossible to attain a totalising view of the city and that the capital's heterogeneity is to be cherished. Treating London as a symbol of modernity, Ford engages in a polemic with contemporary voices who were articulating a narrow version of Englishness. The Soul of London explores a number of related issues: the difficulty of describing a city of personal impressions and knowledges; the contrast between the squalor in which poor people live and the comfort enjoyed by a moneyed class; the city's capacity to embrace all sorts of newcomers, whom it remakes as depoliticised subjects; the need to combat the tentacular reach of bureaucracy with an individualism that is indispensable to civic life; and the fear of metropolitan anonymity, which may act as cover for the violent criminal and the political revolutionary. Because London 'tolerates all the types of mankind', it 'has palaces for the great of the earth, it has crannies for all the earth's vermin' ( $S L$ 12). It is in such nooks and crannies that 'vermin' like the Professor secrete themselves in The Secret Agent, a novel that exploits the paranoid aspects of Ford's description of a liberal and democratic metropolis. Dark anonymous streets create an urban space in which anarchists and police are the interchangeable pawns of a wider system. As one of the novel's anarchists puts it: 'Revolution, legality - counter moves in the same game' (SA 64).

The Soul of London was written at a time of intense political debate about poverty, unemployment, housing, and immigration. Ford's title hints that the identity of the nation is in fact at stake, since so many of the immigrants who came to England settled in London, usually inhabiting the slums of the East End. Anxiety about this influx led to the passing of the Aliens Act in 1905. Racial stereotypes abounded and 
anti-Semitism was rife. Socialists and anarchists did not fall into official 'undesirable' categories, but there was a suspicion that 'London was the secret international headquarters of the [anarchist] movement, where its horrible crimes were planned'. ${ }^{169}$ The restriction of immigration had the double purpose of tackling poverty and combating revolution. The pressure large numbers of new arrivals put on housing and jobs was a major concern, which picked up on existing anxieties about the living conditions of an indigenous underclass. Various sociological texts described the infernal regions into which social explorers had to descend if they were to learn about and aid their benighted denizens. The notion of a civilising mission, which informed imperialist rhetoric, was transferred to slum dwellers, who were often seen as a distinct species. ${ }^{170}$ Jack London wrote of 'a fearful slime that quickened the pavement with life, a mess of unmentionable obscenity $[\ldots]$ a menagerie of garmented bipeds that looked something like humans and more like beasts', while C. F. G. Masterman described a 'new city race' that seemed like 'a sudden unaccountable revelation of an invasion dropped from nowhither'. ${ }^{171}$

These depictions recall H. G. Wells's Martians from The War of the Worlds (1898). The slimy, fungoidal appearance of these extraterritorial invaders fills Wells's narrator with 'strange horror' and overcomes him 'with disgust and dread'. ${ }^{172}$ The Martians are the fantasised embodiment of an alien life form that threatens to take over the human world. Like Dracula's Renfield, 'a zoophagous (life-eating) maniac' who seeks to 'absorb as many lives as he can', the Martians feed off the life force of those they kill: 'They did not eat, much less digest. Instead, they took the fresh, living blood of other creatures, and injected it into their own veins' ${ }^{173}$ There is a link here to jingoist rhetoric about immigration. Arnold White, who agitated on behalf of the Aliens Bill, attacked immigrants for 'replacing English workers and driving to despair men, women and children of our blood' and denounced the 'pauper foreigner' for 'successfully colonising Great Britain under the nose of H.M. Government'. ${ }^{174}$

Ford rejected this xenophobic rhetoric. Insisting that London could overcome differences of racial outlook by assimilating the foreigner, he sought to create a cultural counter-myth in order to tackle the parochial fear of the immigrant. The Soul of London depicts a metropolis that is tolerant, open-minded, and heterogeneous. Nonetheless, there is a flip-side to its humane vision. Ford argued that cultural differences were not maintained in a spirit of diversity in London but were eradicated, transforming 
people into anonymous and standardised modern 'types'. The danger as he saw it was that individuality would be wiped out, with troubling consequences for a civic life dominated by rigid bureaucracies and centralised corporations. Georg Simmel expressed the same anxiety in 'The Metropolis and Mental Life' (1903) when he wrote that 'in buildings and educational institutions, in the wonders and comforts of space-conquering technology, in the formations of community life, and in the visible institutions of the state, is offered such an overwhelming fullness of crystallized and impersonalized spirit that the personality $[\ldots]$ cannot maintain itself under its impact'. ${ }^{175}$ A related anxiety - which is explored at length in Conrad's The Secret Agent (1907) - was that the city camouflaged people, enabling them to engage in criminal or revolutionary activity. Dracula pointedly tells Jonathan Harker: 'I am content if I am like the rest, so that no man stops me if he see me, or pause in his speaking if he hear my words, to say "Ha, ha! A stranger!"176

The Soul of London speaks in various ways to these anxieties about interlopers and criminals. On the one hand, it suggests that the city is the cradle of the modern spirit because it permits a range of ethnic and cultural groups to interact, thereby ensuring the diversity that, for Ford, is indispensable to properly civic life. But on the other hand, it warns that the metropolis can also destroy this heterogeneity because it is a key site of rationalising processes that make life impersonal in the ways identified by such sociologists as Simmel, Ferdinand Tönnies, and Max Weber. The city in The Soul of London is associated with civic pluralism, on the one hand, and with economic forces that threaten individuality, on the other hand. Ford is as aware as Friedrich Engels of capitalism's power to transform workers into 'machines pure and simple' and to atomise everyday life in the process, creating a society that is characterised by 'the unfeeling isolation of each in his private interest'. ${ }^{177}$ Hence Ford's references to 'great organisations run by men as impersonal as the atoms of our own frames, noiseless, and to all appearances infallible' (SL 30), his anger at the destruction of local trades by new technologies, and his fear that mechanised work is eroding individuality, which turns people into unthinking units.

There is a tension in The Soul of London between two conceptions of modernity, one emphasising its cosmopolitanism, the other stressing its insensibility. Ford's main concern is that rationalisation and bureaucratisation are eroding the public sphere. If 'the heaviest indictment that can be brought against a city' is that it 'blunts our sense of individualities' (SL 94), then this is because such blunting undermines 
the basis on which a civilised society depends. The citizens of ancient Athens were not 'more cultured or more wise' than today's populace, but 'they had, each one of them, better chances of influencing all their fellow inhabitants' (SL 95). Present-day society, in contrast, sees 'humanity not as poor individuals but as parts of a theory, as negligible cog-wheels of a passionless machine' for which efficiency and expansion are overriding goals, with a resulting loss 'in our human consciousness and in our civic interests' ( $S L$ 96). Ford's view of what constitutes a healthy polity is nowhere more clear than here: he opposes an empathic view of people that conceives them as thinking and feeling agents to a dehumanizing perspective that sees individuals as machines. The overriding modern fear disclosed by The Soul of London is of a streamlined world run by drones with no power to affect its affairs.

This means that the modern city's capacity to assimilate all-comers may be problematic. How tolerant, really, is a metropolis of which it is written that 'if it finds a place for all eccentricities of physiognomy, of costume, of cult, it does so because it crushes out and floods over the significance of those eccentricities' ( $S L 12)$ ? It is here that Ford's modernist manner of presenting London is so important, for it acts to resist the tendencies he is decrying. The jumble and muddle of London that Ford celebrates resembles a form of literary collage that sees a potential for liberation in diversity. The city's want of harmony symbolises a valuable plurality, which manifests itself not only in the themes Ford tackles but also in the fragmentary form of his text. The Soul of London provides a composite image of the city and in doing so draws attention self-reflexively to its constructed nature as an artefact and to the difficulty of attaining an overarching view - it refuses totalising strategies at the levels of theme and form alike. A syncretic picture is gradually built up, but it never coalesces into a distilled image. On the contrary, London is 'a ragoût of tit-bits' ( $S L 10$ ), a 'hotchpotch' ( $S L$ 6), a 'chaotic crowd' (SL 16), a 'muddle of gray wheel traffic' (SL 16), and the 'queerest jumble of old terraces' ( $S L 36$ ). A site of promiscuous confusion, everything in it is 'all mixed together' so that 'it is not possible to get any zones to "synchronise" ( $S L$ 38). Disorder in the metropolis acts as the guarantor of social diversity and as the source of the text's impressionist and collage-like aesthetic.

But Ford recognises that London, with its 'brooding and sinister glow' (SL 23) and 'gloomy and shadowy depths' (SL 49), is also a dark space blighted by class conflict between two groups who are 'very foreign' and 'very hostile the one to the other' (SL 49). It is full of 'slinking, horribly 
suggestive [...] figures' (SL 17) who hover in the shadows and who have not been assimilated at all. This is the troubling world of The Secret Agent, in which the city is depicted as a 'monstrous town' and 'the cruel devourer of the world's light' ( $S A$ 10). In keeping with its focus on political fear, The Secret Agent stresses the importance of surveillance, the need to monitor undesirable figures in order to prevent them from exploiting the anonymity of the metropolis. In The Secret Agent, the principle of visibility on which surveillance depends fails because urban space does away with identity, frustrating the principle of observation on which surveillance is predicated. When the Assistant Commissioner descends into the 'slimy aquarium' of the metropolis, for instance, 'the genius of the locality assimilate[s] him', turning him into 'one more of the queer foreign fish that can be seen of an evening about there flitting round the dark corners' ( $S A$ 124). Indistinguishable from those he is hunting, the Assistant Commissioner might be one of the aliens who were associated in the popular imagination with revolutionary violence. With all outward signs of his occupation and status erased, he is able to act 'as though he were a member of the criminal classes' who 'linger out of sight' ( $S A$ 126).

Conrad's The Secret Agent and Ford's The Soul of London both register widespread anxieties about the anonymity of the modern metropolis and the dubious activities - criminal and/or political - that can take place under its protective cover. They also differentiate between the city's various districts, making it clear that poverty can always be found near to wealth and suggesting that class conflict could break out into the open at almost any moment. Ford's text is explicit about this. It associates leisure with casual sauntering around the city, a genteel flânerie that is backed by wealth and the sense of security it brings, whereas it depicts labour as an enforced discipline that is hard to endure. There is a tension between those who have the wherewithal to enjoy the pleasures the city offers and those who feel trapped within its industrial and commercial confines. If working-class life conjures up 'a picture of the black plains of the East End' ( $S L 73$ ), then the lives of the privileged appear like 'a square block like a fortress that we all, more or less, are besieging' ( $S L 73$ ). Such imagery crops up in a number of modernist texts. Although Dubliners (1914) deals mainly with a lower-middle-class life that is in danger of sliding into penury, the text also depicts Dublin as a place of poverty. Populated by hordes of 'grimy children' who are seen by one character as 'minute vermin-like life' (D 54), Dublin's 'poor stunted houses' are said to resemble 'a band of tramps, huddled together along the river-banks, their old coats covered 
with dust and soot' (D 55). Towards the end of the text, the whole city appears to be succumbing to the same sort of darkness that mantles Conrad's Heart of Darkness: 'A dull yellow light brooded over the houses and the river; and the sky seemed to be descending' (D 167).

Woolf's The Voyage Out (1915), the first drafts of which were written from around 1910 onwards, registers similar concerns in its opening chapter. A walking figure is assailed by sights and sounds that stir her to thought: 'The shooting motor cars, more like spiders in the moon than terrestrial objects, the thundering drays, the jingling hansoms, and little black broughams, made her think of the world she lived in' (VO 5). Loud noises and frenetic movement combine to produce a picture of the city as a fast-paced and aggressive locus, while the image of automobiles as lunar arachnids indicates that these new machines had not yet become assimilated by the imagination. Something sinister underlies this ceaseless urban energy:

She knew how to read the people who were passing her; there were the rich who were running to and from each others' houses at this hour; there were the bigoted workers driving in a straight line to their offices; there were the poor who were unhappy and rightly malignant. Already, though there was sunlight in the haze, tattered old men and women were nodding off to sleep upon the seats. When one gave up seeing the beauty that clothed things, this was the skeleton beneath. (VO 5)

Rendered through free indirect discourse, the thoughts expressed in this passage disclose a typical turn-of-the century liberal middle-class sensibility. It is at once prejudiced (why should the workers be 'bigoted'?) and sympathetic to others (such beauty as can be discerned in the city is said to conceal distressing poverty).

Ford's view of opposed parts of London besieging each other and Woolf's alertness to the misery just below the surface of urban life have their parallels in Wells's Tono-Bungay, a novel that is best described as 'modern' rather than 'modernist', both in terms of its anti-Jamesian narrative technique and its interest in an up-to-date subject matter: science, technology, business, advertising. His first-person narrator contrasts the East End - 'morbidly expanded, without plan or intention, dark and sinister' - with the 'clean, clear, social assurance of the West End'. Faced with the sheer massiveness of London, the narrator sets out to interpret it, describing his travels through the city as a kind of urban dissection - a 'piece of social comparative anatomy'. This 
medical-anthropological image fits with his wider thesis, which is that London is England in microcosm and that both the capital and the nation are the diseased products 'of some tumorous growth-process'. But this is just one of London's many aspects, which is soon overlaid by another: the city as an 'illimitable place' - as in Ford - that teems with 'suggestions of indefinite and sometimes outrageous possibility, of hidden but magnificent meanings'. ${ }^{178}$ Here the city is the site of energy, freedom, and opportunities for new thoughts, experiences, and lifestyles. It is a place of auditory and visual clamour, one stimulus following another in a riot of competing attractions, as evoked by the sensation-hungry Italian Futurists. For Tono-Bungay's narrator and protagonist, the city also offers opportunities for self-improvement and upward social mobility.

It is impossible for everybody to rise up the social scale, however. The city's diversity can conceal vital social and economic differences. The difficulty of overcoming class divisions is shown with great clarity in Forster's Howards End, where the attempt by the Schlegels to make emotional contact with the clerk Leonard Bast is fraught with insuperable problems, while their efforts to help him backfire spectacularly and result (indirectly) in his death. The Schlegel desire to build 'the rainbow bridge that should connect the prose in us with the passion' (HE 158159 ) by fusing pragmatism with sensitivity is understood in spiritual and personal terms. Howards End calls this approach into question by emphasising other types of connection, not least that between economics and culture. Early on, for example, Margaret Schlegel recognises that her class stands 'upon money as upon islands' (HE 51). This momentary insight leads to the beginnings of a materialist understanding of social inequality, namely, that 'the very soul of the world is economic, and that the lowest abyss is not the absence of love, but the absence of coin' (HE 52). Told that this is a 'cynical' view, Margaret insists that 'below the surface of the sea' (HE 52) from which her money is endlessly renewed there exists a large class of impoverished people. What she is unable to do, however, is make the connection between labour and the creation of wealth. The islands of money just appear to be inevitably there; riches flow upwards from the sea itself. Margaret displays no awareness that those who are below the surface of the water are propping up the islands and that their poverty is a consequence of an economic system that prevents them from breasting the waves. She eventually elides the link between economics and class altogether, claiming that the 'eternal differences' between people are 'planted by 
God in a single family, so that there may always be colour' ( $H E$ 288) and telling her sister to forget Bast. Economic inequality is reinterpreted as social diversity, and the city's role as part of a wider - and increasingly global - system that promotes inequality is forgotten, to be replaced by a preoccupation with the 'earth beating time' (HE 290) as the world is inexorably melted down.

\section{Ford Madox Ford and The English Review}

The city in a text like Howards End is a source of unease, as is its involvement in a global economy that cannot be separated from the unequal exchanges presided over by imperialism and colonialism. But the modern metropolis is also the site of different kinds of exchange - for example, of ideas and artistic practices - which it facilitates by drawing together people from divergent backgrounds and by creating the social spaces that enable them to interact and collaborate. Modernism could not have developed outside these spaces, and it could not have come into being (or survived) were it not for a whole complex of supporting institutions and networks, from friendship groups through to literary agents, patrons, book publishers, anthologists, journals, editors, reviewers, and critics. Of particular importance here was the role played by the little magazines that not only disseminated so much of the writing we associate with modernism (often in the teeth of indifference or censorship) but also set the terms for how it was initially discussed, since so many of the key critical essays about its emerging works appeared in their pages, stimulating debate and encouraging further experiments. Most modernist little magazines, as Peter Brooker and Andrew Thacker have pointed out, 'occupy a position at odds with or opposed to a received mainstream' because they see themselves as standing 'for something better or more modern' than mainstream literature and culture, and it is for this reason that they can be said to belong to a 'counter public sphere or cultural formation'. ${ }^{179}$

The importance of little magazines to the emergence of modernism and to the dissemination of its most significant works can scarcely be overestimated. It was by means of these often short-lived magazines that writers who were keen to challenge literary orthodoxies could put across their alternative views and publish the kind of work they wanted to promote. Little magazines typically had a clear - often intemperate editorial line, were run on tight budgets by individuals or small cadres 
of like-minded partisans, attacked established writers and artistic tendencies, promulgated particular aesthetic and cultural values, and forged group identities. The English Review was one of the most important of the early little magazines. Ezra Pound captures the flavour of what was at stake in such productions in a retrospective comment: "The EVENT of 1909-1910 was Ford Madox (Hueffer) Ford's "English Review," and no greater condemnation of the utter filth of the whole social system of that time can be dug up than the fact of that review's passing out of his hands' ( $P / F$ 164). This is typical not only of the combative Pound but also of a wider modernist attitude: the little magazine is positioned as an irruption in a decadent culture that will eventually defeat it.

Ford did indeed establish The English Review 'with the definite design of giving imaginative literature a chance in England', in keeping with his conviction that 'imaginative literature is the only thing of any permanent worth in the world'. ${ }^{180} \mathrm{He}$ started it in order to publish the kind of writing that other journals were reluctant to accept - the reason for which the majority of little magazines were created. He sometimes claimed that he had embarked on the entire enterprise because nobody else would publish Hardy's 'A Sunday Morning Tragedy', and at other times he suggested the Review had been started in order to print Conrad's A Personal Record (RTY 149). During the brief period that he was its editor (December 1908 to February 1910), he published a wide range of established writers (among them Arnold Bennett, Conrad, John Galsworthy, Hardy, Stephen Hudson, James, George Meredith, Tolstoy, and Wells) and launched the careers of young writers who would go on to become major authors: Rupert Brooke, Lawrence, Lewis, and Pound. Like The New Age under A. R. Orage, which sought to 'encourage a vital relationship between literary experimentation and the literary tradition', The English Review was not programmatically modernist, even if it did a great deal to advance the cause of modernism in England. ${ }^{181}$ Ford, rather, sought to publish work of the highest technical standard (his abiding obsession), and he saw no significant division between an older generation of writers and an emerging one, provided that they were all committed artists. It seemed to him 'that if that nucleus of writers could be got together with what of undiscovered talent the country might hold a Movement might be started' (RTY282).

Ford was hostile to cultural complacency and stuffy morality. Among other things, he wanted to be able to write about sexuality 'without the distortions of bourgeois sentimentality'. ${ }^{182}$ Interestingly, however, 
The English Review looked backwards as much as forwards. It aligned itself with the Aesthetic and Decadent 1890s as much as it forged a new path in the 1910s. Ford suggested that he had 'aimed at founding an aube de siècle Yellow Book' and by doing so had managed to give voice to a new generation of young writers. ${ }^{183}$ Eric Homberger argues that he "helped to define one of the central battlefields of "modern literature", for he sought to make an "English" review a vehicle for cultural cosmopolitanism'. ${ }^{184}$ Ford had long inveighed against the parochial and insular character of English literary life, which he believed needed to be revivified by contact with foreign writers and traditions. Conrad, Crane, Hudson, and James were the figures who in his estimation rejuvenated post-Victorian literature. They 'lit in those days in England a beacon that posterity shall not easily let die', Ford averred, asking his readers 'to consider how empty, how lacking a nucleus, English literature would today be if they had never lived' (RTY22).

Ford's advocacy of conscious artistry (backed up by the claim that he valued 'style' over 'content') might suggest that he was a formalist and an aesthete. He wrote, for example: 'I have always held that Art exists for the purpose of Art alone and that you cannot have any perfect work of art unless in the execution the artist have put out of his head all thought save the thought of that execution'. ${ }^{185}$ This is potentially misleading, however. Ford's obsession with good writing did not mean that he had no interest in its social dimension or its accessibility. On the contrary, he argued that literature (and the novel, above all) could explore the most urgent issues of the day better than any other art form and that it should be addressed not to a self-appointed elite but to the common reader. Modernists have been charged with a deliberate and exclusionary obscurity, but this accusation cannot be levelled at Ford, who wrote that '[a]ccording to the measure of [the] artist's identity with his species, so will be the measure of his temporal greatness' (FCW 48). The 'business of the artist', Ford wrote, 'is to awaken thought in the unthinking' and what this 'amounts to in practice is that the artist should consider himself as writing for the uninstructed man bonae voluntatis' ( $C A$ 64) because the 'excuse for the existence of the artist is that he voices the unvocal of his own type' (CA 65).

The English Review served several purposes. It promoted the claims of younger writers, defended the conscious artistry that was central to Ford's aesthetics, and published work that engaged with modern life in all its bewildering aspects. The authors whom Ford valued tended to be craftsmen who took the task of writing as seriously as he did, and his 
editorials for The English Review insisted on this point. In his introductory remarks to The Critical Attitude (1911), the book in which he collected his English Review editorials, he argued that chief among the Review's purposes had been 'the furthering of a certain school of literature and of a certain tone of thought' ( $C A 4)$. The latter, he explained, should be conceived as 'a critical attitude' ( $C A 4$ ). But Ford maintained that the creation of a specifically 'English' literary journal on these lines was 'a contradiction in terms' ( $C A 4$ ) because the English were hostile to critical thinking and conscious artistry alike. Since 'nothing will make the Englishman adopt a critical attitude' ( $C A$ 5), The English Review should have been regarded as one of those 'insane enterprises' ( $C A 4$ ) that had no hope of succeeding in its aims. This rhetoric served a polemical purpose, but it also expressed Ford's belief that the literature that dominated early twentieth-century English culture was failing to engage with a society in which established values were being challenged or overthrown. An intellectually and artistically serious literature was needed to explore the changing face of modern life.

What, then, did Ford mean by a 'critical attitude'? He was concerned above all with the rise of specialists who prevented ordinary people from participating in the democratic process. For Ford, a growing culture of expertise was producing an atomised society in which key decisions were made by professional elites, while the public at large was kept in ignorance: 'All questions have become so exceedingly complicated, there is so little opening for moral fervour that the tendency of the great public is more and more to leave all public matters in the hands of a comparatively few specialists. Practical politics have become so much a matter of sheer figures that the average man, dreading mathematics almost as much as he dreads an open mind, is reduced, nevertheless, to a state of mind so open that he has abandoned thinking - that he has abandoned even feeling about any public matter at all' ( $C A 114)$. For Ford, the more difficult it was to make sense of reality, the more the task of doing so was allotted to technicians who were experts in their narrow fields but were incapable of providing an overarching analysis of society. The artist, Ford claimed, 'is the only man who, in a world grown very complicated through the limitless freedom of expression for all creeds and moralities, can place before us how those creeds work out when applied to human contacts, and to what goal of human happiness those moralities will lead us' (CA 27-28). Ford's overarching concern in The English Review was to assert the social value of the 
arts by arguing that they played an indispensable role in the maintenance of a properly functioning public sphere.

The English Review presented itself as a journal that aimed to counteract the maleficent influence of writing that failed to engage with contemporary reality. The 'chief value of the arts to the State', Ford wrote, 'is that they are concerned with Truth', and 'if, at present, the arts have very little place in the economy of the nation, it is that they devote themselves comparatively little to the life that we really live' ( $C A$ 26). Conscious artistry was needed as never before, since modernity was characterised by a ceaseless disassembling and reassembling in new forms of earlier modes of life. Daily reality, Ford argued, was 'so fragile, so temporary, so evanescent' that it appeared as though 'modern life were a dance of midges' ( $C A$ 186). This description of contemporary existence indicates why Ford's impressionism needs to be seen as a key feature of the socially embedded and culturally sensitive modernism to which his work made such an important contribution. For the broader point at issue here is that Ford's conception of modernity as the site of perpetual change informed his belief that the arts were a vital component of the body politic and that impressionism was the literary means par excellence that enabled modern writing indirectly to contribute to social life, even if it could not - as Wells proposed - ameliorate it. Because 'it has become almost impossible to see any pattern in the carpet' ( $C A 28$ ) of contemporary life, imaginative literature was urgently needed, since it alone could make partial sense of it. Ford thus insisted on the inseparability of the arts from the public sphere. The English Review was created in the hope of discovering whether there exists in these islands any trace of a sober, sincere, conscientious, and scientific body of artists, crystallising $[\ldots]$ modern life in its several aspects' and 'for the definite and unashamed purpose of promoting such a school, were it found to exist, or did it seem possible to found one' ( $C A 29$ ).

Paradoxically, this view of the arts actually conceived them as a form of specialisation and was thus part of the modernising logic Ford wanted to contest. For the conscious artist - a skilled technician and expert in the craft of writing - is as much a specialist as the technocrats whose baleful influence Ford sought to resist. Put another way, art was to be the specialisation to end all specialisations. It had the capacity, Ford argued, to embrace the fragmented professional practices that characterised modernity and then see beyond them. No less important was Ford's belief in artistic centres (national academies of 
the arts) and in literature as a discipline requiring commitment to the pursuit of excellence - another form of professionalism. If literature was unable to grasp the whole of reality, then this revealed that modern life had become complex, but it did not undermine the arts' aspiration to be a comprehensive specialisation. In response to this predicament, he suggested that in the future 'there may rise up a great many of finer specialists, each of whom will be a Great Figure. This is all the hope there is for Thought and for the Arts' (CA 129). The English Review, in short, resisted specialisation inasmuch as it exacerbated social fragmentation but defended it in the artistic sphere on the grounds that "life is a thing so complicated that only in the mirror of the arts can we have a crystallised view or any vicarious experience at all' and that 'only from the arts can any safety for the future of the State be found' ( $C A$ 29). It was to defend this conception of modern literature's importance to the body politic that The English Review had been created.

The English Review was important because of the writers it published, the work it introduced, the careers it helped to get going, the challenge it mounted to accepted attitudes, the continuities it established with an earlier nineteenth-century avant-garde tradition that went back through The Yellow Book to the Pre-Raphaelites, and the impetus it gave to others who started up magazines of a similar type. Eric Homberger suggests that Ford's editorials for The English Review 'do not quite make up a sacred book of modernism, but they brilliantly define the doctrines upon which a modernism could be erected'. ${ }^{186}$ This view chimes with Max Saunders's claim that the 'period of literary modernism is "the Ford Era" as much as it is Pound's, T. S. Eliot's, or Joyce's' and that Ford was 'a central transforming force of early English modernism'. ${ }^{187}$ Ford seemed to recognise what might be called the 'transitional' nature of The English Review. Certainly, he saw it as smoothing a path for radicals like Lewis and Pound. As he put it in Return to Yesterday: 'The English Review seemed then profoundly to have done its work. Ezra and his gang of young lions raged through London. They were producing an organ of their own. It was called - prophetically - Blast' (RTY 311). Ford both welcomes his own supersession and, crucially, questions it, for he suggests that The English Review had paved the way for les jeunes and that without it their iconoclasm might have struggled to have the impact that it did. Ford, then, can be seen to be passing on the torch. If The English Review had been a twentieth-century version 
of The Yellow Book, then Blast was a more radical development of The English Review under Ford, which, in the short time that he edited it, did so much to promote the modernists who would soon become so influential. Cliff Wulfman justly observes that in Ford's hands The English Review' 'was a watershed in the history of English letters and a contribution to the making of modernism, articulating with astonishing freshness the continental "critical attitude" and launching the careers of some of the twentieth century's most celebrated writers in English'. ${ }^{188}$

The English Review was at once Edwardian and modernist. It looked backwards and forwards at the same time. It also celebrated a cosmopolitanism that Ford associated with the beneficent influence of European and American writers. Indeed, Ford claimed that Conrad was responsible for the title of The English Review and 'felt a certain sardonic pleasure in the choosing so national a name for a periodical that promised to be singularly international in tone' (RTY 284). Ford relished what Wells described as a 'ring of foreign conspirators plotting against British letters' (RTY21) at the turn of the century. For Ford, the work accomplished by these seditionists, aided by his English Review, helped to bring about a gradual transition in English literary and cultural life from the hypocrisy he associated with the Victorian age to the conscious artistry and the vigour of a whole range of interconnected (though also different) modernisms: impressionism, Imagism, Italian Futurism, and Vorticism. These various groups represented 'another foreign invasion' (RTY312) - another challenge to English insularity and parochialism - and their aim was to conquer London, the metropolitan centre that had to be seized if their vision of the arts was to gain a hearing and, so they hoped, radically transform the culture of their time. Ford welcomed their energy and ideas, even though he recognised that their aggressive avant-gardism in some cases sought to do away with the impressionism to which he was devoted and which he had championed as a quintessentially modernist form of writing.

This raises an interesting question. If Ford had paved the way for this avant-gardism and was associated with it (the first part of The Good Soldier appeared in Blast, for example), was he then willing to accept that the early modernism he had championed belonged to an earlier phase of the literary and cultural renewal he had done so much to promote? In the relatively late Return to Yesterday (1931), Ford wrote with reference to the 1914 period: 'Impressionism was dead. 
The day of all those explosive sounds had come' (RTY 312). There is the sense here that at that time Ford had temporarily felt that he was being superseded by the very writers he had encouraged and whose uncompromising avant-gardism appeared to be somehow more modern than his own impressionism. Actually, this is a coy rhetorical move, for Ford's real point is that the onrushing First World War would swiftly do away with impressionism and Vorticism alike - as Lewis also recognised in Blasting and Bombardiering (1937). Return to Yesterday presents Ford as bowing out in 1914, but at the time he wrote it he well knew that he had returned triumphantly in the 1920s with his impressionist masterpiece Parade's End. And he had continued to champion impressionism - in his 1924 book on Conrad especially - in the 1920s, as he also would do in the 1930s, when he defended its merits in The March of Literature (1939). ${ }^{189}$ Ford, in other words, continued to advocate impressionism as if it were still alive, and not killed off by Futurism and Vorticism. His faith in its methods once again discloses modernism's multifarious nature, its irreducibility to a single style, form, or movement.

\section{Notes}

1 Thomas Hardy, Jude the Obscure, ed. C. H. Sisson (Harmondsworth: Penguin, 1985), 42.

2 See Lyn Pykett, Engendering Fictions: The English Novel in the Early Twentieth Century (London: Edward Arnold, 1995), especially 16-17.

3 Bonnie Kime Scott, ed., The Gender of Modernism: A Critical Anthology (Bloomington and Indianapolis: Indiana University Press, 1990), 3 and 4.

4 Sarah Grand, 'The New Aspect of the Woman Question', in A New Woman Reader: Fiction, Articles, Drama of the 1890s, ed. Carolyn Christensen Nelson (Peterborough, Ontario: Broadview Press, 2001), 141-145, 143 .

5 Ella Hepworth Dixon, 'Character Note: The New Woman', in The Fin de Siècle: A Reader in Cultural History, 1880-1900, ed. Sally Ledger and Roger Luckhurst (Oxford: Oxford University Press, 2000), 80-88, 86.

6 Jane Eldridge Miller, Rebel Women: Feminism, Modernism and the Edwardian Novel (London: Virago, 1994), 4.

7 'Socio-Literary Portents', Speaker (December 22, 1894), 684 and Laura Marholm Hansson, Studies in the Psychology of Woman, trans. Georgia A. Etchinson (Chicago and New York: Herbert S. Stone, 1899), 301.

8 H. G. Wells, Ann Veronica [1909] (London: Virago, 1980), 49 and 144. 
9 Max Nordau, Degeneration, trans. George L. Mosse (New York: Howard Fertig, 1968), 16 and 17.

10 See Patrick Brantlinger, The Reading Lesson: The Threat of Mass Literacy in Nineteenth-Century British Fiction (Bloomington and Indianapolis: Indiana University Press, 1998) and John O. Jordan and Robert L. Patten, ed., Literature in the Marketplace: Nineteenth-Century British Publishing and Reading Practices (Cambridge: Cambridge University Press, 1995).

11 Wells, Ann Veronica, 8 and 20.

12 Sally Ledger, 'The New Woman and Feminist Fictions', in The Cambridge Companion to the Fin de Siècle, ed. Gail Marshall (Cambridge: Cambridge University Press, 2011), 153-168, 154.

13 Mona Caird, 'Marriage', in Ledger and Luckhurst, The Fin de Siècle, $77-80,77$.

14 Olive Schreiner, The Story of an African Farm [1883] (Harmondsworth: Penguin, 1986), 27.

15 Ruth Robbins, Pater to Forster, 1873-1924 (Houndmills: Palgrave Macmillan, 2003), 170.

16 Quoted by Ledger in Egerton, KD, xiii.

17 Havelock Ellis, The New Spirit (London: George Bell, 1890), 9.

18 Olive Schreiner, Woman and Labour [1911] (London: Constable, 1998), 103.

19 Hugh M. Stutfield, 'Tommyrotics', in Ledger and Luckhurst, The Fin de Siècle, 120-126, 124.

20 Quoted in Pykett, Reading Fin De Siècle Fictions, 49-50.

21 See Deborah Longworth, 'Gendering the Modernist Text', in The Oxford Handbook of Modernisms, ed. Peter Brooker, Andrzej Gąsiorek, Deborah Longworth, and Andrew Thacker (Oxford: Oxford University Press, 2010), 156-177.

22 Quoted in Ledger and Luckhurst, The Fin de Siècle, 105.

23 Wells, Ann Veronica, 273.

24 Schreiner, The Story of an African Farm, 210.

25 George Egerton, 'A Keynote to "Keynotes"', in John Gawsworth, Ten Contemporaries: Notes Toward Their Definitive Biography (London: Ernest Benn, 1932), 57-60, 58.

26 May Sinclair, 'The Novels of Dorothy Richardson', in The Gender of Modernism: A Critical Anthology, ed. Bonnie Kime Scott (Bloomington and Indianapolis: Indiana University Press, 1990), 442-448, 442-443.

27 For detailed accounts, see Miranda Seymour, A Ring of Conspirators: Henry James and his Literary Circle (London: Hodder and Stoughton, 1988) and Nicholas Delbanco, Group Portrait: Joseph Conrad, Stephen Crane, Ford Madox Ford, Henry James and H. G. Wells (London: Faber, 1982). Ford in 1913 published his Henry James: A Critical Study (London: Martin Secker, 1913), a work in which he described James as 'the greatest writer now living' (17). 
28 See, for example, Ford Madox Ford [as Ford Madox Hueffer], Thus to Revisit: Some Reminiscences (London: Chapman \& Hall, 1921), 29.

29 Ibid., 40.

30 Oscar Wilde, The Complete Works of Oscar Wilde (London: Collins, 1990), 341.

31 H. G. Wells, Tono-Bungay, ed. Edward Mendelson [1909] (Harmondsworth: Penguin, 2005), 14.

32 Max Saunders, 'Ford and Impressionism', in Ford Madox Ford: Literary Networks and Cultural Transformations, ed. Andrzej Gąsiorek and Daniel Moore, International Ford Madox Ford Studies 7 (Amsterdam: Rodopi, 2008), 151-166, 154.

33 Saunders, 'Ford and Impressionism', 157. See also Jesse Matz, Literary Impressionism and Modernist Aesthetics (Cambridge: Cambridge University Press, 2001).

34 Woolf, 'Modern Fiction', 9.

35 See Peter D. McDonald, British Literary Culture and Publishing Practice, 1880-1914 (Cambridge: Cambridge University Press, 1997).

36 See also Ford Madox Ford, 'Pure Literature', Agenda: Ford Madox Ford Double Issue 22. 4/28. 1 (Winter 1989/Spring 1990), 5-22.

37 Henry James, The House of Fiction: Essays on the Novel (London: Mercury, 1962), 42-43.

38 Ibid., 43.

39 Joseph Conrad, The Mirror of the Sea and a Personal Record, ed. Zdzisław Najder (Oxford: Oxford University Press, 1989), xv and Joseph Conrad, The Collected Letters of Joseph Conrad, Volume 1: 1861-1897, ed. Frederick R. Karl and Laurence Davies (Cambridge: Cambridge University Press, 1983), 253.

40 Ford Madox Ford, Mightier Than the Sword (London: George Allen and Unwin, 1938), 134 and 135.

41 Ford claimed in Mightier Than the Sword that he 'never read Hardy, whom [he] understood to represent reasoned revolt against Established Anglicanism', because he 'wanted a plague on both those houses' (123).

42 Lionel Johnson, The Art of Thomas Hardy: 1840-1928 (London: John Lane the Bodley Head, 1923), 32 and 173.

43 For James's criticisms of Hardy, see Philip Horne, ed., Henry James: A Life in Letters (London: Allen Lane, 1999), 249.

44 James, The House of Fiction, 271.

45 Florence Emily Hardy, The Life of Thomas Hardy (London: Macmillan, 1962), 228-229.

46 Thomas Hardy, The Collected Letters of Thomas Hardy, Volume 6: 1920-1925, ed. Richard Little Purdy and Michael Millgate (Oxford: Clarendon Press, 1987), 48. 
47 Charles Baudelaire, 'The Painter of Modern Life', in Selected Writings on Art and Artists, trans. P. E. Charvet (Cambridge: Cambridge University Press, 1981), 402 and 403.

48 Thomas Hardy, Selected Letters, ed. Michael Millgate (Oxford: Clarendon Press, 1990), 182.

49 Ibid., 182.

50 Ibid., original emphasis. Hardy respected James's writing, although he had doubts about aspects of his work. See Selected Letters, 156.

51 Conrad, The Collected Letters, Volume 1, 416.

52 Joseph Conrad, Notes on Life and Letters (London: J. M. Dent \& Sons, 1921), 69. See also John G. Peters, Conrad and Impressionism (Cambridge: Cambridge University Press, 2001), 170.

53 For the concept of delayed decoding, see Ian Watt, Conrad in the Nineteenth Century (Berkeley and Los Angeles: University of California Press, 1979).

54 Edel and Ray, Henry James and H. G. Wells, 200.

55 Horne, Henry James, 530.

56 Joseph Conrad, Selected Literary Criticism and The Shadow-Line, ed. Allan Ingram (London: Methuen, 1986), 34.

57 Ibid., 53.

58 Allon White, The Uses of Obscurity: The Fiction of Early Modernism (London: Routledge \& Kegan Paul, 1981), 16 and 24.

59 Conrad, Selected Literary Criticism, 34, 35, and 35-36.

60 Joseph Conrad, Conrad's Prefaces to His Works (London: J. M. Dent \& Sons, 1937), 60-61.

61 Peters, Conrad and Impressionism, 35. See also Adam Parkes, A Sense of Shock: The Impact of Impressionism on Modern British and Irish Writing (Oxford: Oxford University Press, 2011), 3.

62 Matthew Arnold, Culture and Anarchy, ed. J. Dover Wilson (Cambridge: Cambridge University Press, 1988), 35.

63 Walter Pater, The Renaissance: Studies in Art and Poetry [1873], ed. Adam Phillips (Oxford: Oxford University Press, 1990), xxix.

64 Conrad, Selected Literary Criticism, 34.

65 Ibid., 35-36.

66 Watt, Conrad in the Nineteenth Century, 195.

67 Conrad, Selected Literary Criticism, 32.

68 Ibid., 33.

69 Hardy, Selected Letters, 145.

70 Conrad, The Collected Letters, Volume 1, 425.

71 Friedrich Nietzsche, On the Genealogy of Morals/Ecce Homo, trans. Walter Kaufman and R. J. Hollingdale (New York: Vintage, 1969), 44.

72 Matthew Arnold, 'Preface to First Edition of Poems' [1853], in Matthew Arnold, On the Classical Tradition, ed. R. H. Soper 
(Ann Arbor: University of Michigan Press, 1960), 1-15, 1. For more on hyper-reflexivity, see Louis A. Sass, Madness and Modernism: Insanity in the Light of Modern Art, Literature and Thought (Harvard Massachusetts: Harvard University Press, 1994).

73 Epictetus, Discourses and Selected Writings, trans. and ed. Robert Dobbin (Harmondsworth: Penguin, 2008), xii.

74 Ibid., 123.

75 See Andrea White, Joseph Conrad and the Adventure Tradition: Constructing and Deconstructing the Imperial Subject (Cambridge: Cambridge University Press, 1993).

76 See Joseph Conrad, The Mirror of the Sea, 92.

77 See John MacKenzie, ed., Imperialism and Popular Culture (Manchester: Manchester University Press, 1986) and Robert H. MacDonald, The Language of Empire: Myths and Metaphors of Popular Imperialism, 18801918 (Manchester: Manchester University Press, 1994).

78 See Richard Shannon, The Crisis of Imperialism, 1865-1915 (London: Hart-Davis, Macgibbon, 1974), 218-219.

79 J. A. Hobson, 'Capitalism and Imperialism in South Africa', Contemporary Review (January 1900), 1-17, 1 and 15.

80 A. P. Thornton, The Imperial Idea and Its Enemies: A Study in British Power (London: Macmillan, 1985), 109.

81 Patrick Brantlinger, Rule of Darkness: British Literature and Imperialism, 1830-1914 (Ithaca: Cornell University Press, 1988), 33. See also William Greenslade, Degeneration, Culture and the Novel, 1880-1940(Cambridge: Cambridge University Press, 1994), 30.

82 Simon Gikandi, Maps of Englishness: Writing Identity in the Culture of Colonialism (New York: Columbia University Press, 1996), 161; Timothy Brennan, 'Postcolonial Studies Between the European Wars: An Intellectual History', in Marxism, Modernity, and Postcolonial Studies, ed. Crystal Bartolovich and Neil Lazarus (Cambridge: Cambridge University Press, 2003), 185-203, 189.

83 Edward Said, 'Representing the Colonised', Critical Inquiry 15 (Winter 1989), 205-225, 222-223.

84 Edward W. Said, Culture and Imperialism (London: Vintage, 1994), 188. For a broader account of his interest in the construction of identity in relation to various 'others', see Edward W. Said, 'Afterword', in Orientalism: Western Conceptions of the Orient (Harmondsworth: Penguin, 1995), 329-377.

85 Michael Bell, Literature, Modernism and Myth: Belief and Responsibility in the Twentieth Century (Cambridge: Cambridge University Press, 1997), 149. For a similar argument about 'modernist form' as 'an adequate means of representing [the] terrifying appeal of feminism and socialism', see Marianne DeKoven, Rich and Strange: Gender, 
History, Modernism (Princeton, New Jersey: Princeton University Press, 1991), 4.

86 Fredric Jameson, 'Modernism and Imperialism', in Terry Eagleton, Fredric Jameson, Edward W. Said, Nationalism, Colonialism and Literature (Minneapolis and London: University of Minnesota Press, 1990), 43-68, 44 and 51.

87 Jameson, 'Modernism and Imperialism', 64. For a critique of this argument, see Patrick Williams, "“Simultaneous Uncontemporaneities": Theorising Modernism and Empire', in Modernism and Empire, ed. Howard J. Booth and Nigel Rigby (Manchester: Manchester University Press, 2000), 13-38.

88 Ford Madox Ford, England and the English, ed. Sara Haslam (Manchester: Carcanet, 2003), 244.

89 Paul Gilroy, The Black Atlantic: Modernity and Double Consciousness (London: Verso, 1993), 17.

90 John A. McClure, Late Imperial Romance (London: Verso, 1994), 8.

91 Joseph Conrad, Almayer's Folly: A Story of an Eastern River [1895] (London: Gresham, 1925), vii.

92 Ibid.

93 Ibid., viii.

94 Edward W. Said, Culture and Imperialism (London: Vintage, 1994), 28.

95 T. H. S. Escott, England: Its People, Polity, and Pursuits (London: Chapman and Hall, 1885), 3.

96 Jonathan Schneer, London 1900: The Imperial Metropolis (New Haven: Yale University Press, 1999), 13.

97 Richard Ruppel, 'Heart of Darkness and the Popular Exotic Stories of the 1980s', Conradiana 21. 1 (1989), 3-14, 9.

98 See Michael Valdez Moses, The Novel and the Globalization of Culture (Oxford: Oxford University Press, 1995).

99 Laura Chrisman, 'Rethinking the Imperial Metropolis of "Heart of Darkness"', in Conrad at the Millennium: Modernism, Postmodernism, Postcolonialism, ed. Gail Fincham and Attie de Lange with Wiesław Krajka (Lublin: Marie Curie-Skłodowska University, 2001), 399-426, 414.

100 McClure, Late Imperial Romance, 12.

101 Daniel Just, 'Between Narrative Paradigms: Joseph Conrad and the Shift from Realism to Modernism from a Genre Perspective', English Studies 89. 3 (June 2008), 273-286, 275.

102 Karl Marx, The Eighteenth Brumaire of Louis Bonaparte, trans. Daniel de Leon (Chicago: Charles H. Kerr, 1914), 9.

103 Jameson, 'Modernism and Imperialism', 54.

104 For a detailed reading of this scene, see Mark Wollaeger, Modernism, Media, and Propaganda: British Narrative from 1900 to 1945 (Princeton: Princeton University Press, 2006). 
105 See $S H 39,130,145$, and 167. For discussions of Joyce and egoism, see Jean-Michel Rabaté, James Joyce and the Politics of Egoism (Cambridge: Cambridge University Press, 2001). More broadly, for the importance of egoism to modernism, see David Kadlec, Mosaic Modernism: Anarchism, Pragmatism, Culture (Baltimore: Johns Hopkins Press, 2000).

106 Christopher Innes, 'Modernism in Drama', in The Cambridge Companion to Modernism, ed. Michael Levenson (Cambridge: Cambridge University Press, 1999), 130-156, 131.

107 See H. G. Wells, 'The Contemporary Novel' (1911): 'You see now the scope of the claim I am making for the novel; it is to be the social mediator, the vehicle of understanding, the instrument of selfexamination, the factory of customs, the criticism of laws and institutions and of social dogmas and ideas'. Edel and Ray, Henry James and H. G. Wells, 154 .

108 Toril Moi has criticised the way this opposition between realism and modernism sidelines drama in many accounts of modernism in Henrik Ibsen and the Birth of Modernism: Art, Theater, Philosophy (Oxford: Oxford University Press, 2006), 17-36.

109 Theodor Adorno, Walter Benjamin, Ernst Bloch, Bertolt Brecht, Georg Lukács, Aesthetics and Politics, ed. Ronald Taylor (London: Verso, 2002), 82.

110 Jan McDonald, The 'New Drama' 1900-1914(London and Basingstoke: Macmillan, 1986), 5.

111 Thomas Postlewait, Prophet of the New Drama: William Archer and the Ibsen Campaign (Westport, Connecticut: Greenwood Press, 1986), 131.

112 Bernard Shaw, Major Critical Essays (Harmondsworth: Penguin, 1986), 147.

113 Tyrone Guthrie, Theatre Prospect (London: Wishart \& Co., 1932), 45.

114 McDonald, The 'New Drama', 7.

115 See Candida Lacey, ed., How the Vote Was Won and Other Suffragette Plays (London: Methuen, 1985); Maggie B. Gale and Gilli Bush-Bailey, ed., Plays and Performance Texts by Women, 1880-1930 (Manchester: Manchester University Press, 2012); Naomi Paxton, The Methuen Drama Book of Suffrage Plays (London: Methuen Drama, 2013); and Katharine Cockin, Glenda Norquay and Sowon S. Park, ed., Women's Suffrage Literature (London: Routledge, 2007).

116 Jean Chothia, English Drama of the Early Modern Period, 1870-1940 (London and New York: Longman, 1996), 49.

117 Ibid., 13.

118 See Rex Pogson, Miss Horniman and The Gaiety Theatre, Manchester (London: Salisbury Square, 1952), 8.

119 Ibid., 72. For a list of the plays put on at the Gaiety, see Pogson's Appendix A (199-205). For more detail on Horniman's life and work, 
see the Annie Horniman Papers at the John Rylands Library (University of Manchester).

120 Huntly Carter, The New Spirit in Drama and Art [1912] (Milton Keynes: General Books, 2012), 1.

121 Ibid., 2.

122 Ibid., 5.

123 Ibid., 17.

124 Quoted in Edward Craig, Gordon Craig: The Story of His Life (London: Victor Gollancz, 1968), 173.

125 Edward Gordon Craig, On the Art of the Theatre, ed. Franc Chamberlain (London: Routledge: 2009), 145.

126 Christopher Innes, Edward Gordon Craig (Cambridge: Cambridge University Press, 1983), 112-113.

127 Quoted in Innes, Edward Gordon Craig, 122.

128 Carter, The New Spirit, 26.

129 Quoted in Denis Bablet, The Theatre of Gordon Craig, trans. Daphne Woodward (London: Eyre Methuen, 1966), 196.

130 Craig, Gordon Craig, 199.

131 Innes, Edward Gordon Craig, 213.

132 Ashley Dukes, The World to Play With (Oxford: Oxford University Press, 1928), 17-18.

133 Edward Gordon Craig, Craig On Theatre, ed. Michael J. Walton (London: Methuen, 1983), 40.

134 Ibid., 84.

135 Vassily Kandinsky, Complete Writings on Art, ed. Kenneth C. Lindsay and Peter Vergo (New York: Da Capo Press, 1994), 160 and 381.

136 Edward Gordon Craig, A Living Theatre: The Gordon Craig School, The Arena Goldoni, The Mask; Setting Forth the Aims and Objects of the Movement and Showing by Many Illustrations the City of Florence [and] the Arena (Florence, 1913), 3.

137 Craig, On the Art of the Theatre, 90.

138 Clifford Bax, ed., Florence Farr, Bernard Shaw, W. B. Yeats: Letters (London: Home \& Van Thal, 1946), 29.

139 Ashley Dukes, The Scene is Changed (London: Macmillan, 1942), 7.

140 Ibid., 31.

141 Craig, Gordon Craig, 182-188.

142 Edward Gordon Craig, Index to the Story of My Days: Some Memoirs of Edward Gordon Craig 1872-1907 (Cambridge: Cambridge University Press, 1981), 235-236.

143 Craig, On the Art of the Theatre, xiv. For the view that Craig and Barker were forerunners of a British theatrical avant-garde, see Claire Warden, British Avant-Garde Theatre (Houndmills, Basingstoke: Palgrave Macmillan, 2012), 63. 
144 Bablet, The Theatre of Edward Gordon Craig, 111.

145 Chothia, English Drama, 81.

146 Wilhelm Worringer, Abstraction and Empathy: A Contribution to the Psychology of Style [1908], trans. Michael Bullock (Chicago: Ivan R Dee, 1997), 3.

147 Quoted in Craig, Index, 238 and 239.

148 Quoted in Innes, Edward Gordon Craig, 121.

149 Innes, Edward Gordon Craig, 143.

150 For an account of the Pound-Yeats relationship, see James Longenbach, Stone Cottage: Pound, Yeats, and Modernism (Oxford: Oxford University Press, 1990).

151 Craig, Craig on Theatre, 21.

152 Ibid.

153 Ibid., 23.

154 Yvan Goll, 'Two Superdramas', in Walter H. Sokel, ed., An Anthology of German Expressionist Drama: A Prelude to the Absurd (New York: Doubleday, 1963), 9-11, 10.

155 Alfred Jarry, The Ubu Plays, trans. Kenneth McLeish (London: Nick Hern, 2010), $x$.

156 Quoted in Alastair Brotchie, Alfred Jarry: A Pataphysical Life (Cambridge, Massachusetts: The MIT Press, 2011), 30.

157 Ibid., 90.

158 Heinrich von Kleist, 'On the Marionette Theatre', in Hand to Mouth and Other Essays, trans. Idris Parry (Manchester: Carcanet, 1981), 9-18, 16.

159 Craig, Craig on Theatre, 85, 86, and 87.

160 W. B. Yeats, Autobiographies, ed. William H. O'Donnell and Douglas N. Archibald (New York: Scribner, 1999), 266.

161 R. F. Foster, W. B. Yeats: A Life, Volume 1. The Apprentice Mage: 1865-1914 (Oxford: Oxford University Press, 1997), 210.

162 For more on primitivism in this context, see Christopher Innes, AvantGarde Theatre, 1892-1992 (London: Routledge, 1993).

163 See Peter Brooker, Bohemia in London: The Social Scene of Early Modernism (London: Palgrave Macmillan, 2007).

164 Friedrich Nietzsche, Human, All Too Human: A Book for Free Spirits, trans. R. J. Hollingdale (Cambridge: Cambridge University Press, 1996), 378.

165 Raymond Williams, Politics of Modernism: Against the New Conformists (London: Verso, 2007), 45 and 46. See also Terry Eagleton, Exiles and Emigrés. For another version of this argument, see George Steiner, Extraterritorial: Papers on Literature and the Language Revolution (Harmondsworth: Penguin, 1971).

166 Peter Brooker, 'Modernism and the Fiction of the City', in The Oxford History of The Novel in English, Volume 4: The Reinvention of the British 
and Irish Novel 1880-1940, ed. Patrick Parrinder and Andrzej Gąsiorek (Oxford: Oxford University Press, 2011), 353-369, 357 and 358.

167 Williams, Politics of Modernism, 46.

168 Scott McCracken, 'Imagining the Modernist City', in Brooker et al., The Oxford Handbook of Modernisms, 637-654, 644.

169 Bernard Gainer, The Alien Invasion: The Origins of the Aliens Act of 1905 (New York: Crane, Russak, 1972), 101.

170 See James Grant, The Great Metropolis, Volume 1 (New York and London: Garland, 1885).

171 Jack London, The People from the Abyss [1903] (London: Pluto, 1998), 13 and 114; C. F. G. Masterman, From the Abyss: Of its Inhabitants by One of Them [1902] (New York and London: Garland, 1980), 4.

172 H. G. Wells, The War of the Worlds (London: J. M. Dent, 1998), 19 and 20.

173 Bram Stoker, Dracula, ed. Maurice Hindle (Harmondsworth: Penguin, 1993), 95; Wells, The War of the Worlds, 119.

174 Quoted in William J. Fishman, East End Jewish Radicals, 1875-1914 (London: Duckworth, 1975), 70 and 71.

175 Georg Simmel, 'The Metropolis and Mental Life', in The City Cultures Reader, ed. Malcolm Miles, Tim Hall, and Iain Borden (London: Routledge, 2001), 12-19, 19.

176 Stoker, Dracula, 31-32.

177 Friedrich Engels, The Condition of the English Working Class (London: Lawrence \& Wishart, 1984), 42 and 60.

178 H. G. Wells, Tono-Bungay, ed. Edward Mendelson [1909] (Harmondsworth: Penguin, 2005), 80, 81, and 84.

179 Peter Brooker and Andrew Thacker, The Oxford Critical and Cultural History of Modernist Magazines, Volume I: Britain and Ireland 1880-1955 (Oxford: Oxford University Press, 2009), 29.

180 Ford Madox Ford, Letters of Ford Madox Ford, ed. Richard M. Ludwig (Princeton, New Jersey: Princeton University Press, 1965), 40.

181 Wallace Martin, The New Age Under Orage: Chapters in English Cultural History (Manchester: Manchester University Press, 1967), 3.

182 Max Saunders, Ford Madox Ford: A Dual Life, Volume 1: The World Before the War (Oxford: Oxford University Press, 1996), 242.

183 Ford, Thus to Revisit, 58.

184 Eric Homberger, 'Ford's English Review: Englishness and its Discontents', in Agenda: Ford Madox Ford Special Double Issue 27. 4/28.1 (Winter 1989/Spring 1980): 61-66, 66.

185 Ford, 'Pure Literature', 10.

186 Homberger, 'Ford's English Review', 66.

187 Saunders, Ford Madox Ford, Volume 1, v and vi. 
188 Cliff Wulfman, 'Ford Madox Ford and The English Review (1908-37)', in Brooker et al., The Oxford Critical and Cultural History of Modernist Magazines, Volume I, 226-239, 239.

189 See Ford Madox Ford, Joseph Conrad (London: Duckworth, 1924) and Ford Madox Ford, The March of Literature: From Confucius' Day to Our Own [1939] (Normal, Illinois: Dalkey Archive, 1994). 